\title{
Mitigation of Autoignition Due to Premixing in a Hypervelocity Flow Using Active Wall Cooling
}

\author{
Erik Axdahl* and Ajay Kumar ${ }^{\dagger}$ \\ NASA Langley Research Center, Hampton, VA 23681 \\ Alan Wilhite $\ddagger$ \\ National Institute of Aerospace, Hampton, VA 23666
}

\begin{abstract}
Preinjection of fuel on the forebody of an airbreathing vehicle is a proposed method to gain access to hypervelocity flight Mach numbers. However, this creates the possibility of autoignition either near the wall or in the core of the flow, thereby consuming fuel prematurely as well as increasing the amount of pressure drag on the vehicle. The computational fluid dynamics code VULCAN was used to conduct three dimensional simulations of the reacting flow in the vicinity of hydrogen injectors on a flat plate at conditions relevant to a Mach 12 notional flight vehicle forebody to determine the location where autoignition occurs. Active wall cooling strategies were formulated and simulated in response to regions of autoignition. It was found that tangential film cooling using hydrogen or helium were both able to nearly or completely eliminate wall autoignition in the flow domain of interest.
\end{abstract}

\section{Nomenclature}

\begin{tabular}{ll}
\multicolumn{2}{l}{ Alphabetic } \\
$A$ & Reaction rate coefficient \\
$B$ & Blowing parameter \\
$c$ & Species concentration \\
$d$ & Dimensional quantity \\
$D_{h}$ & Hydraulic diameter \\
$E$ & Activation energy \\
$k_{f}$ & Forward reaction rate \\
$L$ & Length \\
$\dot{m}$ & Mass flow rate \\
$n$ & Temperature exponent \\
$P$ & Porosity \\
$R$ & Universal gas constant \\
$T$ & Temperature \\
$W$ & Width \\
$x, y, z$ & Cartesian coordinates
\end{tabular}

*Aerospace Engineer, Hypersonic Airbreathing Propulsion Branch, MS168, Member AIAA

${ }^{\dagger}$ Distinguished Research Associate, Systems Analysis and Concept Directorate, Fellow AIAA

${ }^{\ddagger}$ Professor, Department of Aerospace Engineering, Georgia Institute of Technology, Associate Fellow AIAA 
Greek

$\beta \quad$ Ramp sweep angle

$\begin{array}{ll}\text { Subscript } \\ 1,2 & \text { Major and minor dimensions, respectively } \\ c & \text { Combustion } \\ e & \text { Exit } \\ \text { cool } & \text { Coolant condition } \\ i & \text { Main flow condition } \\ i n j & \text { Main injector condition }\end{array}$

\section{Introduction}

continuing goal for research in supersonic combustion ramjet (i.e. scramjet) propulsion is access to
higher Mach numbers. This goal is driven by the desire to integrate a scramjet engine into a transatmospheric vehicle airframe to improve single- and two-stage-to-orbit system performance. On trajectories extending beyond Mach 10, however, conventional scramjet systems are projected to experience a significant loss in efficiency, eventually approaching that of a conventional rocket. Among the reasons for this loss as Mach number increases, the available time decreases to inject and mix fuel with the supersonic internal airstream and complete the combustion process.

The state of the art for propulsion in the hypervelocity regime (i.e. above Mach 10) is advanced by taking advantage of premixed, shock-induced combustion (PMSIC). An example of an engine using this technique is the shock-induced combustion ramjet (i.e. shcramjet). In a shcramjet, fuel is injected on the vehicle forebody where it mixes with the captured air stream, after which the fuel-air mixture enters the inlet/combustor where a shock wave induces ignition. Because the mixing occurs on the forebody, the combustor is significantly shortened allowing for lower weight and a reduced heat load. A reduced heat load will mitigate or eliminate the amount of excess fueling (i.e. fueling above the design flow rate to increase the fuel cooling capacity) required to cool the engine, thereby increasing the specific impulse of the shcramjet over the scramjet.

PMSIC technical challenges that must be overcome are indicated in Figure 1. First is the ability to achieve uniform mixing of the fuel and air along the forebody without spillage from the cowl lip or significant loss in stream thrust potential. ${ }^{1,2}$ Second is the prevention of autoignition of the fuel-air mixture as fuel enters the hot boundary layer of the forebody or as hot gas from the boundary layer is entrained into the fuel plume. ${ }^{3}$ Third is the issue of shock wave stability due to combustion at conditions characteristic of the entrance to the combustor. ${ }^{4-7}$ Consequences of not meeting these technical challenges include combustion instability due to nonuniform mixing, adverse pressure drag on the forebody due to premature combustion, and loss of engine performance due to fuel spillage.

The objective of this research was to understand the mechanisms of autoignition due to fuel-air premixing on a hypervelocity forebody and to develop strategies to minimize autoignition in this flow regime. Three injection cases were considered-flush-wall, ramp, and strut injection-with the geometry of each case taken from the authors' previous study of forebody injection and mixing. ${ }^{2}$ Regions of autoignition were identified along with the circumstances from which autoignition arises for each case. Autoignition mitigation through the use of film cooling and wall transpiration were considered as active cooling strate- 


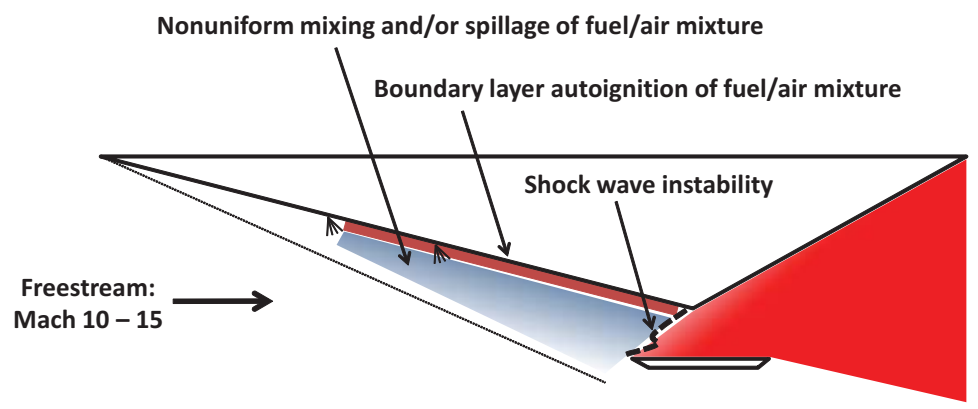

Figure 1. Some key challenges posed by using a PMSIC-enabled shcramjet system are shown.

gies to inhibit the presence of autoignition near the wall.

\section{Active Cooling Strategies}

The premixed or mixing flow on a hypervelocity forebody shares a cooling requirement with an internal flowpath in that basic structure survivability requires surface temperatures and heat loads below material limits. However, forebody flows have an additional requirement to minimize (and hopefully eliminate) the presence of ignition until the entrance of the combustor is reached. Premature burning not only consumes fuel before the fuel/air mixture can reach the combustor, but it also produces drag on the vehicle due to elevated pressures on the forebody. As with scramjets, shcramjets are likely to operate on a thin margin of thrust - the introduction of additional drag and thrust losses (both through premature fuel consumption) may create design and mission infeasibility.

Both film cooling and transpiration concepts have been studied a great deal in the literature and are used in many different aerospace systems encountering high heat load conditions. They have been considered and used for the protection of rocket nozzles, ${ }^{8}$ supersonic inlets, ${ }^{9}$ gas turbine blades, ${ }^{10-12}$ nose cones, ${ }^{13}$ reentry vehicles, ${ }^{14}$ and rocket combustors, to name a few. They are generally distinguished in that film cooling works by injecting a cooled gas near the body through a tangential slot or line of injectors and transpiration cooling injects gas through an array of drilled or fabricated perforations in the wall. Both concepts alter the thermal structure of the wall boundary layer as well as convect heat away from areas of high heat load.

Most of the literature has a single-objective desire to lower heat loads at and traveling through the wall. In essence, high temperatures experienced away from the wall are of little consequence as long as they don't affect the wall heating. For such a case, a film or transpiration cooler that uses a combustible gas such as hydrogen as its coolant performs well if the hydrogen is successfully able to keep the surface cool even if the edge of the cooling layer begins to combust due to the high temperatures in that region. ${ }^{15}$ Similarly, if the primary flow is composed with a fuel, burning on the coolant edge is also acceptable as long as heat loads remain low at the wall. This is because for a cooling concept occurring internally in a combustion chamber additional burning occurring away from the wall is not necessarily a detriment (and possibly is a benefit) - a combustor is not a region where ignition mitigation is desired. For a forebody flow, however, this is a disastrous outcome because of the increased wall pressure and associated forebody drag. Therefore, this study concentrates on the effect of different cooling strategies on the ignition characteristics observed in the flow.

The secondary gases in this study were chosen to be hydrogen, helium, or nitrogen. Hydrogen was considered because it is the same gas as the fuel and, therefore, would only require the system to provide a single fuel storage solution. It also has a high heat capacity by mass, which will possibly provide for lower temperatures as the transpired gas mixes with the main flow. A detriment to using hydrogen is its chemical 
activity as it readily and rapidly burns.

Helium and nitrogen provide respectively low and high molecular weight alternatives to hydrogen as secondary gases. Their primary benefit compared to the use of hydrogen is that they are both inert at the temperatures of interest in the current study. Both have detriments compared to hydrogen in that they would require separate storage and cryogenic cooling requirements from the fueling system. In addition, nitrogen has poor heat capacity by mass compared to hydrogen, although it is a inexpensive and prevalent. Helium can provide a comparable heat capacity by mass to hydrogen, although it is more expensive and less available than nitrogen.

\section{Modeling and Simulation}

\section{Fuel Injector Geometries}

The fuel injectors in this study were chosen among those evaluated by Axdahl et al. ${ }^{2}$ for nonreacting fuel injection and mixing on a notional Mach 12 vehicle forebody. Transverse, ramp, and strut injection were evaluated and the best performer in each category was used in this study. These top performers included the stinger-shaped flush-wall injector (Figure 2), the unswept ramp injector with converging base (Figure 3), and the strut injector (Figure 4). These injectors were chosen because they had the greatest ratio of stream thrust potential to mixing efficiency compared to other injectors simulated in the same class. The injector conditions used in this study are given in Table 1 . The transverse injector conditions were chosen to ensure sonic injection at a matched dynamic pressure ratio to the crossflow. The ramp and strut injector conditions were chosen to be pressure matched to the upstream crossflow conditions.

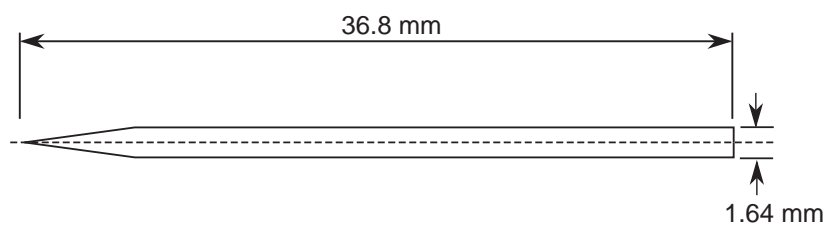

Figure 2. The nozzle exit geometry for the transverse injector is shown.

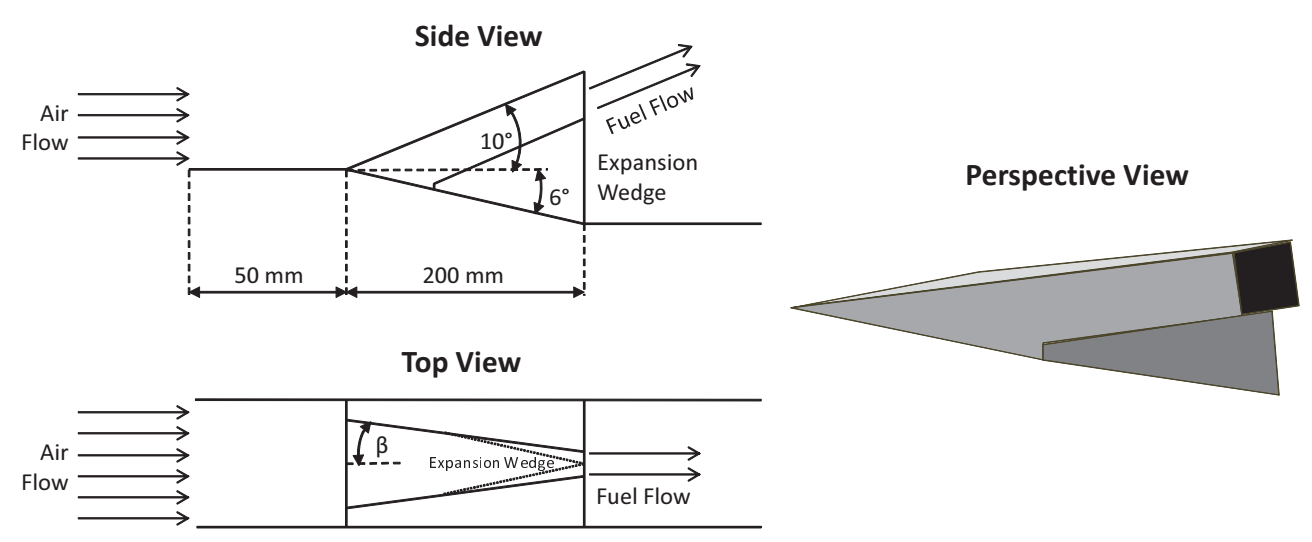

Figure 3. The geometry of the ramp injector situated on an expansion ramp is shown with the converging base feature. 

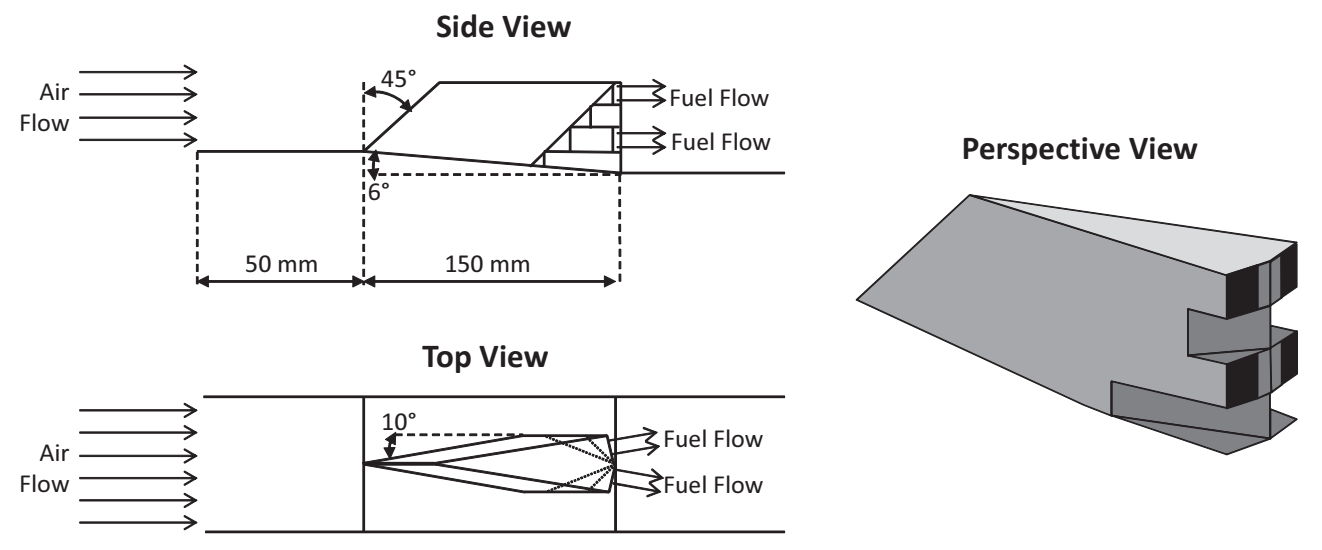

Figure 4. The geometry of the strut injector situated on an expansion ramp is shown.

Table 1. Fuel injector exit conditions by Axdahl et al. ${ }^{2}$ All cases use $100 \% \mathrm{H}_{2}$ at a static temperature of $390 \mathrm{~K}$.

\begin{tabular}{rccc}
\hline \hline & Transverse & Ramp & Strut \\
\hline Injector Mach number & 1.00 & 3.92 & 2.60 \\
Dynamic pressure ratio & 1.00 & 0.26 & 0.26 \\
Static pressure & $535 \mathrm{kPa}$ & $9.11 \mathrm{kPa}$ & $9.11 \mathrm{kPa}$ \\
Injector exit area & $52.6 \mathrm{~mm}^{2}$ & $790 \mathrm{~mm}^{2}$ & $790 \mathrm{~mm}^{2}$ \\
\hline \hline
\end{tabular}

\section{Computational Domain}

The computational grids have approximately 5.8 - 7.8 million grid points with clustering near the injector location and wall. Figure 5 shows the computational domain for the strut injector for illustrative purposes. The computational domain is representative of one-half of the physical domain by using a symmetry boundary condition along the flow centerline bisecting the injector. All walls are set to be isothermal surfaces at a temperature of $500 \mathrm{~K}$. The inflow boundary is fixed at the conditions given in Table 2, representative of conditions on the second ramp on a notional Mach 12 vehicle forebody. The inflow boundary also contains a boundary layer with a $10 \mathrm{~mm}$ thickness in order to model the boundary layer buildup on a forebody. Shocks that would otherwise appear due to forebody flow turning have been ignored for this study.

A $10 \mathrm{~mm}$ portion of each fuel injection tube was simulated with slip walls; thus, the effects of boundary layer buildup and vorticity production within the injector nozzle were neglected. For each domain, there was a $50 \mathrm{~mm}$ ramp leading up to the injector, which occupies a $713 \mathrm{~mm}$ long region until cowl closure. The distance between the injector centerline and the halfway point between neighboring injectors is $34.5 \mathrm{~mm}$.

Table 2. Freestream and flat plate conditions. Flat plate conditions are obtained by shocking the freestream flow through a $5^{\circ}$ turning followed by a $6^{\circ}$ turning. All cases use an air molar composition of $79 \% \mathrm{~N}_{2}$ and $21 \% \mathrm{O}_{2}$.

\begin{tabular}{rcc}
\hline \hline & Freestream & Flat Plate \\
\hline Static pressure & $713 \mathrm{~Pa}$ & $9111 \mathrm{~Pa}$ \\
Static temperature & $232 \mathrm{~K}$ & $541 \mathrm{~K}$ \\
Mach number & 12.0 & 7.67 \\
\hline \hline
\end{tabular}




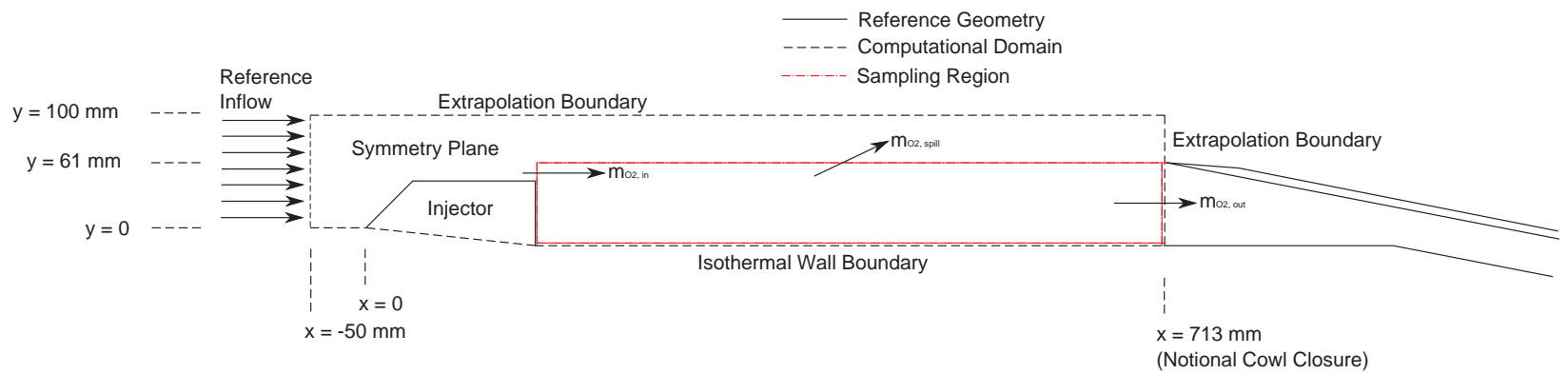

Figure 5. A side-view schematic is shown of the computational domain along with the reference geometry used. A sampling region is indicated that defines how oxygen flow (including spillage) is defined for determining oxygen consumed in the system. The sampling region extends the full width of the computational domain.

\section{Computational Method}

The analysis code used to simulate the computational domain was the Viscous Upwind aLgorithm for Complex flow ANalysis (VULCAN), ${ }^{16}$ developed and maintained at NASA Langley Research Center. VULCAN uses a finite-volume, cell-centered scheme for solving calorically- or thermally-perfect flows on a structured grid. The fluid for this study was assumed to be viscous, thermally perfect, and reacting. The flow was integrated spatially using the Edwards low dissipation flux vector split scheme (LDFSS) scheme ${ }^{17}$ was combined with a 3rd order MUSCL interpolation strategy to provide computational robustness and discontinuity resolution. The flow was integrated temporally using the DAF scheme ${ }^{18}$ with local time stepping and an increasing CFL number schedule. The numerical stiffness introduced by the finite-rate chemistry was handled in a point-implicit manner with the use of a numerical Jacobian. Turbulence was modeled using the two-equation Menter k- $\omega$ model ${ }^{19}$ with a turbulent Prandtl number of 0.9 and turbulent Schmidt number of 1.0. Wall matching functions ${ }^{20}$ were used for wall-bounded areas of the solution domain to relax boundary layer resolution requirements.

\section{Chemistry Modeling}

The chemical model used in this study was that of Jachimowski, ${ }^{21}$ which was developed specifically for the conditions found in high-speed combustion such as for scramjets. For this particular model, chemical reactions involving hydrogen peroxide $\left(\mathrm{H}_{2} \mathrm{O}_{2}\right)$ were removed since they do not have a significant effect on the high temperature combustion environment. ${ }^{22}$ Nitrogen chemistry was also assumed to be unimportant to the current flow regime and was removed. Reactions involving nitrogen were also removed, which stems from the assumption of nitrogen acting largely as an inert species at these conditions.

\section{Wall Transpiration}

For computational simplicity, fluid flow through transpiration injection ports was modeled using a representative bleed model rather than gridding and simulating distinct wall holes and a plenum. This allowed rapid evaluation of the effect of different porosities and mass flows without altering the grid topology. Note that the use of such a model is particularly attractive for blowing studies because of the insensitivity of the transpiration process to the shear stress at the wall for this case. ${ }^{23}$ The ability of VULCAN to accurately model this phenomenon has been studied by Baurle and Norris. ${ }^{24}$

A blowing parameter is defined in order to control the amount of coolant flowing into the wall boundary layer. This parameter is a function of the mass flow rate both through the primary injector and through the 


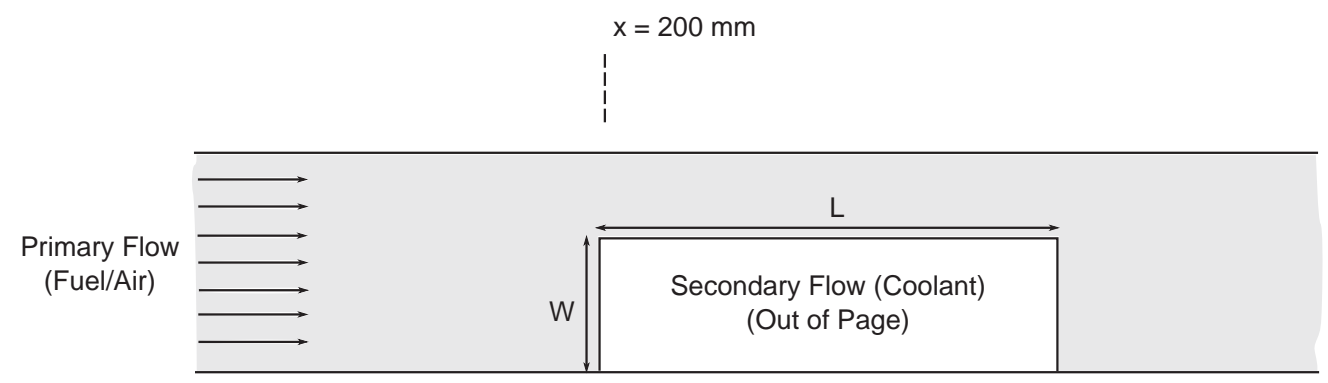

Figure 6. Schematic diagram of wall transpiration.

coolant injector and is defined as

$$
B=\frac{\dot{m}_{\text {cool }}}{\dot{m}_{\text {cool }}+\dot{m}_{\text {inj }}}
$$

where $\dot{m}_{\text {cool }}$ is the mass flow rate issuing from the film or transpiration cooler and $\dot{m}_{i n j}$ is the mass flow rate issuing from the fuel injector.

The transpiration conditions used in the study are given in Table 3 for the transpiration schematic shown in Figure 6. The transpiration model parameters under the user's control in VULCAN are the mass flow through the surface, the total temperature of the fluid in the plenum, the transpiration fluid species, and the porosity of the wall. The porosity is defined as the ratio of the combined area of the transpiration holes in the wall to the total area of the transpiration wall. The porosity for this study was set to be $2 \%$ in order to create the greatest possible plenum pressure. It is also the lower limit of applicability for the transpiration model. The total temperature of the coolant was set to be near the wall temperature. Besides the species and blowing parameter, the size of the transpiration patch was another variable for the current study.

Table 3. Transpiration array conditions

\begin{tabular}{rc}
\hline \hline Blowing parameter $(B)$ & $5.0-20.0 \%$ \\
Wall porosity $(P)$ & $2.0 \%$ \\
Coolant total temperature & $500 \mathrm{~K}$ \\
Wall temperature & $500 \mathrm{~K}$ \\
Coolant species & $\mathrm{H}_{2}, \mathrm{He}$, and $\mathrm{N}_{2}$ \\
\hline
\end{tabular}

\section{Film Cooling}

The mass flow rate supplied to the film cooler, like the transpiration case, was parameterized in terms of the blowing parameter defined in Equation 1. Other parameters to be studied include the species injected and the exit temperature of the film cooling channel, summarized in Table 4 for the schematics shown in Figure 7.

The current study was limited to concepts that contain a substantial axially-directed component. Three configurations were tested: parallel injection, $10^{\circ}$ injection, and $45^{\circ}$ injection. Parallel injection was chosen to provide the least disturbance possible to the primary flow, while the $10^{\circ}$ and $45^{\circ}$ injection cases will both necessarily create a shock wave and some flow deflection. The reason for testing these angled film cooling concepts was to deflect the hot shear layer away from the wall and to see if such benefits offset the creation of a shock wave and higher temperatures between the film cooling shock and the coolant flow. 


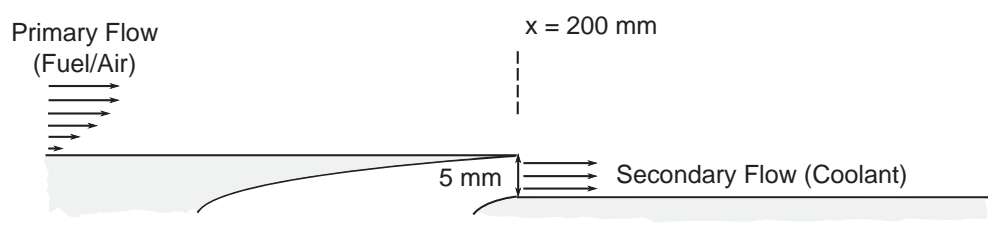

(a)

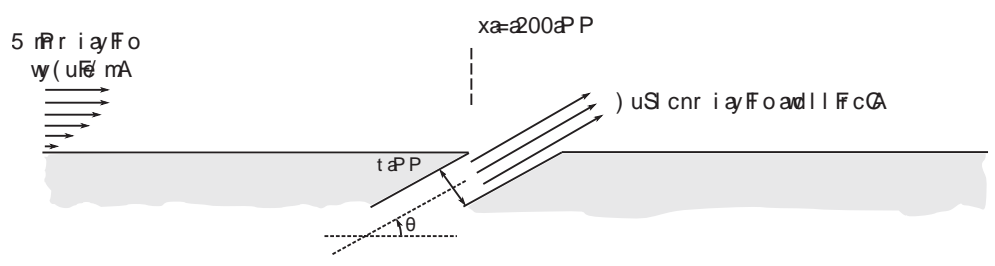

(b)

Figure 7. Schematic diagrams of film cooling via a slot for both (a) tangential and (b) angled injection.

Table 4. Film cooling conditions

\begin{tabular}{rc}
\hline \hline Blowing parameter $(B)$ & $5.0-20.0 \%$ \\
Channel height & $5 \mathrm{~mm}$ \\
Injection angle & $0^{\circ}, 10^{\circ}$, and $45^{\circ}$ \\
Exit temperature & $100,740 \mathrm{~K}$ \\
Species & $\mathrm{H}_{2}, \mathrm{He}$, and $\mathrm{N}_{2}$ \\
\hline \hline
\end{tabular}

\section{Measures of Oxygen Consumption}

For the performance sampling region notionally shown in Figure 5, reactants entering the system are spilled in some proportion relative to the inflow. Because hydrogen is typically in excess for the flows studied here, oxygen was the limiting species that was tracked. Figure 8 shows a notional plot of oxygen mass flow as a function of distance along the body for both a reacting and nonreacting simulation. The two main quantities of interest for computing combustion efficiency, nonreacting and burned mass flow rates, are indicated in the figure. Note that in order to obtain the burned oxygen mass flow rate, both a nonreacting and reacting simulation of the same flow are required.

Once the nonreacting and reacting mass flow rates are obtained for a particular case, it is relatively

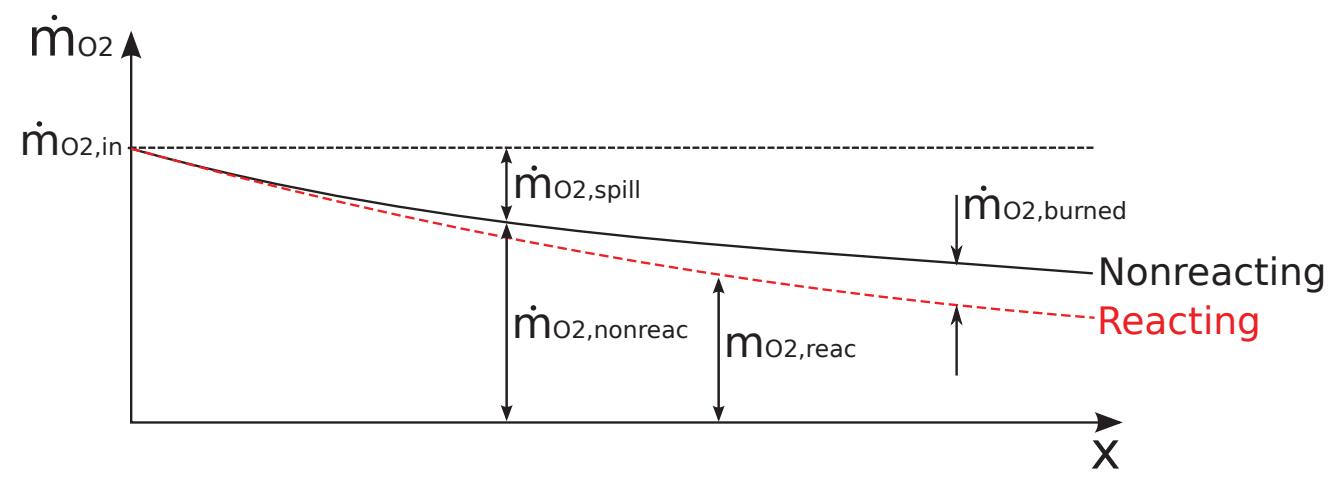

Figure 8. Notional oxygen mass flow rates as a function of distance along sampling region with spilled and burned quantities indicated. 
straightforward to define a combustion efficiency parameter that satisfies the requirements that it be equal to zero when no burning has occurred at a particular location and equal to unity when all available oxygen at a particular flow station has been consumed. The combustion efficiency metric that takes into account reactant spillage is defined as

$$
\eta_{c}=\frac{\dot{m}_{O_{2}, \text { burned }}}{\dot{m}_{O_{2}, \text { nonreac }}}=1-\frac{\dot{m}_{O_{2}, \text { reac }}}{\dot{m}_{O_{2}, \text { nonreac }}}
$$

To obtain the combustion efficiency at a particular station, the reactant mass flow rate for the nonreacting and reacting simulation must be obtained.

For comparing the burning for different cooling methods and conditions, a more general metric was used, the change in oxygen consumed in the sampling region. Different cooling methods and coolant injection conditions will change the spillage properties of a particular geometry being analyzed. Therefore, spillage must be taken into effect directly in the metric measuring oxygen consumed. This equation, using Figure 8 as a reference, is

$$
\dot{m}_{\mathrm{O}_{2}, \text { burned }}=\dot{m}_{\mathrm{O}_{2}, \text { in }}-\dot{m}_{\mathrm{O}_{2}, \text { spill }}-\dot{m}_{\mathrm{O}_{2}, \text { out }}
$$

The change in oxygen burned can then be computed by evaluating this expression separately for the baseline reacting geometry and for the cooled geometry being investigated, subtracting the former from the latter.

\section{Results and Discussion}

\section{Baseline Simulations of Autoignition}

For the present results, the geometries shown in Figures 2, 3, and 4 were simulated at the conditions in Table 1. Upon convergence, chemical induction and ignition were tracked by the formation of hydroxyl $(\mathrm{OH})$ radicals. For the purposes of this study, ignition was defined to be located at points in the flow where $\mathrm{OH}$ appeared at a concentration of at least $0.005 \mathrm{~kg} / \mathrm{m}^{3}$, based on convention found in the literature. ${ }^{25}$ Because the fuel is pure hydrogen, water was the only major product and was also tracked in the flow.

The converged solution of the flush-wall injector showed the greatest amount of chemical reaction of the three injector concepts tested. Figure 9 shows centerline and cross-stream slices of $\mathrm{OH}$ concentration and water mass fraction. The $\mathrm{OH}$ contours are good indicators of where ignition begins. Two primary ignition points are evident: behind the bow shock of the injector plume and laterally on the centerline between neighboring injectors. The ignition region behind the bow shock appears to contribute the most to the combustion occurring in the flow by wrapping the entire fuel plume in shock-heated air and causing ignition as hydrogen diffuses out of the fuel rich plume. It is unclear how such an ignition zone can be mitigated, especially from wall-cooling strategies, because this ignition zone is caused by high temperatures behind the bow shock and away from the wall, not high temperatures in the boundary layer.

The secondary region of ignition on the symmetry plane between neighboring injectors was due to high vorticity that entrained fuel and mixed it with the hot boundary layer near the symmetry plane. This created a large, high-temperature region that subsequently ignited. Such autoignition may be mitigated by wall transpiration in the locality of the symmetry plane.

A plot of combustion efficiency as a function of distance bethind the flush-wall injector is shown in Figure 10. In this plot the amount of combustion throughout the flowfield was quantified and accounts for spillage in the computation. It is observed that by the time the outflow plane was reached, the combustion efficiency achieved a value of $45 \%$, indicating extensive combustion and fuel depletion. While this may be a good trend for internal combustion, it is a bad trend for forebody injection. Because shock-heating of the air plays an important role in the trend, film cooling may be an infeasible approach for autoignition 


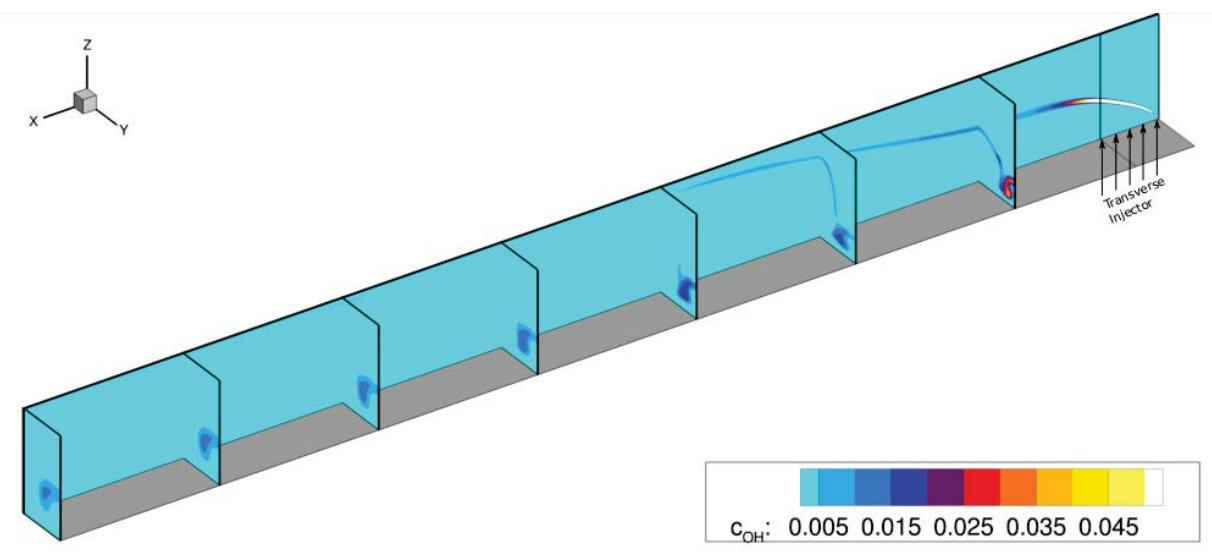

(a)

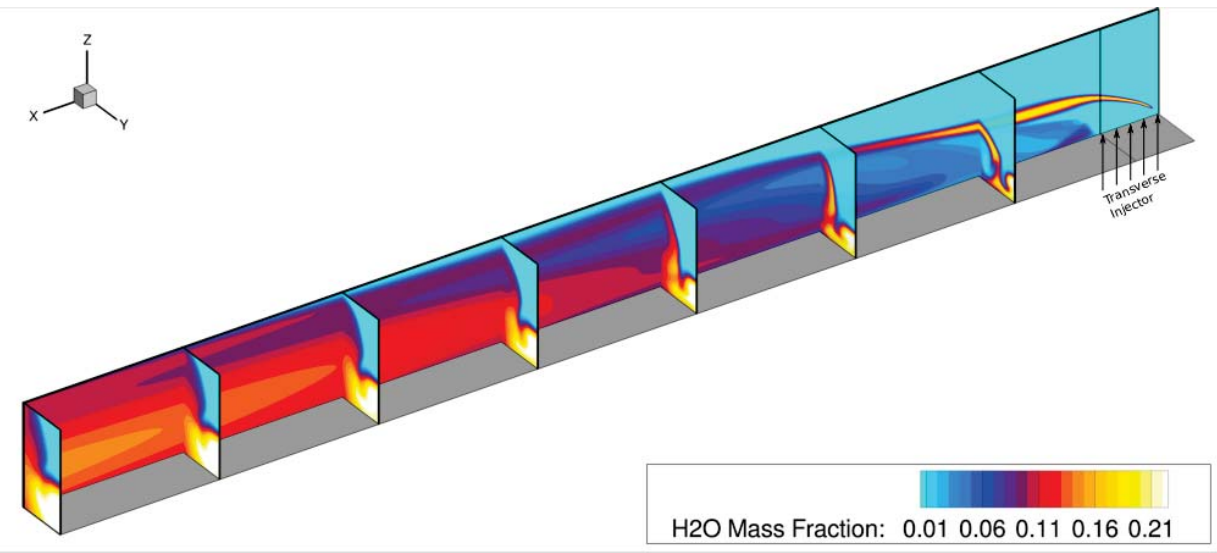

(b)

Figure 9. Stinger injector contours of (a) $\mathrm{OH}$ concentration and (b) water mass fraction in the flow domain of interest. Flow is in the postive $x$-direction. 


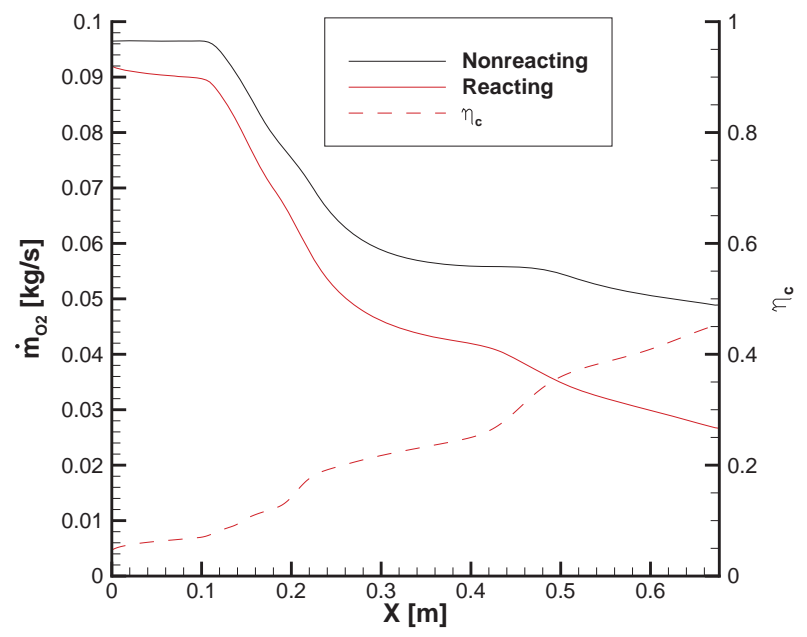

Figure 10. Mass flow rates of oxygen and combustion efficiency downstream of stinger without autoignition mitigation.

mitigation. The high losses experienced by the transverse injector in a previous study ${ }^{7}$ combined with the present autoignition characteristics disqualifies transverse injection as a feasible method for forebody injection for the injector conditions studied here.

The strut injector experienced a moderate amount of autoignition in the wake behind the injector. Two distinct zones of ignition are observed, one away from the wall in the fuel plume vortex and another at the wall, both shown in Figure 11. Shock interactions behind the strut cause subsequent ignition which is extinguished relatively rapidly as the products are folded into the cooler fuel plume. Downstream of the first ignition point, a second ignition occured at the wall as the fuel plume entered into the hot boundary layer region. Downstream of the second ignition point combustion is sustained near the wall, evident by the continuous production of $\mathrm{OH}$ at the wall. While the ignition region at the wall may be addressed by wall cooling, the small ignition region in the fuel plume may require modification to the injector geometry for complete autoignition mitigation. The extent of the combustion occurring for the strut concept is shown quantitatively in Figure 12. Much lower levels of combustion are evident (as compared with the transverse injector concept) with combustion efficiency approaching only around $12 \%$.

The ramp injector experienced a very small region of autoignition downstream of the injector at the wall and near the outflow plane. It was again observed that ignition occured near a region where the fuel entered the hot boundary layer near the flow domain exit. Because this is the only zone of autoignition in the flow and it is near the wall, wall cooling is a strong candidate for mitigating ignition in this area.

Through investigation of autoignition for the transverse, strut, and ramp, the strut injector distinguishes itself as an attractive candidate for further study in autoignition mitigation. The flush-wall injector is not an attractive candidate for further study simply due to the large extent of combustion present, its difficulty for mitigation, and other losses incurred even without reaction present. Similarly, the ramp injector is not an attractive candidate to study due to its general redundancy with the strut case. Like the strut, it shows autoignition once the fuel plume enters into the hot boundary layer. Its main distinction is that this effect occurs farther downstream than the strut injector. It can be assumed that strategies that are successful for the strut injector will also be successful for the ramp injector. Therefore, the study of autoignition mitigation strategies will concentrate on the strut injector from this point onward. 


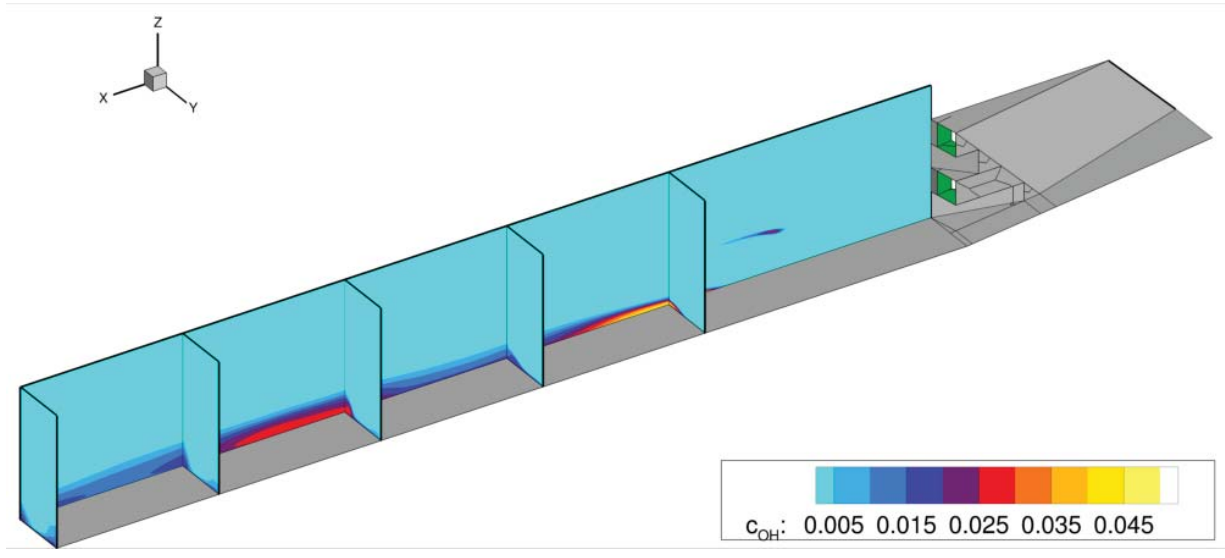

(a)

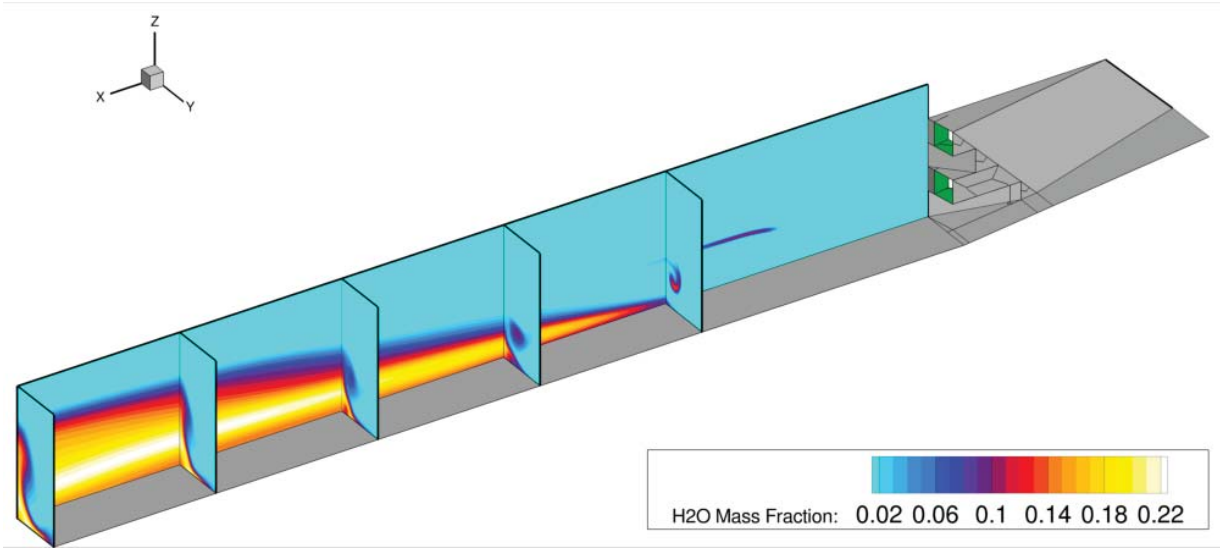

(b)

Figure 11. Ramp injector contours of (a) $\mathrm{OH}$ concentration and (b) water mass fraction in the flow domain of interest. Flow is in the postive $\mathrm{x}$-direction.

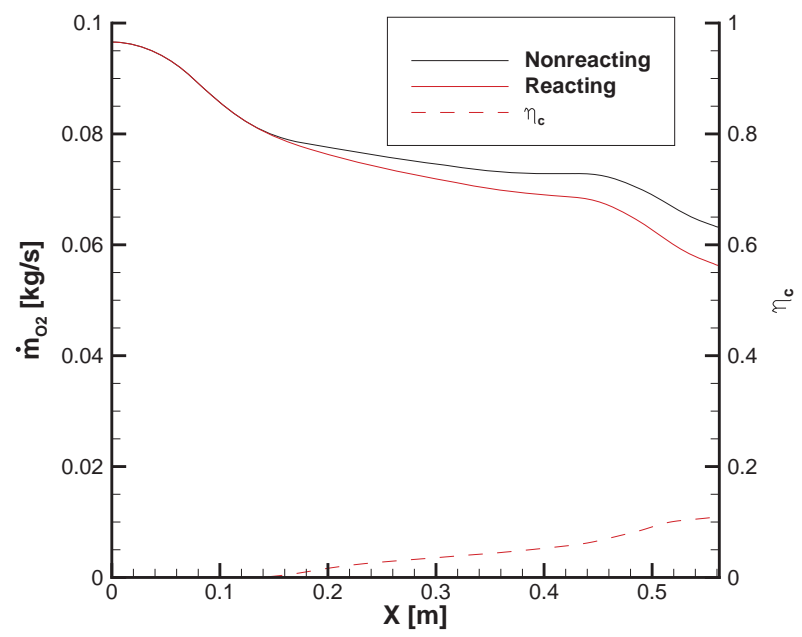

Figure 12. Mass flow rates of oxygen and combustion efficiency downstream of strut without autoignition mitigation. 
Table 5. Coolant mass flow rates for each value of blowing parameter.

\begin{tabular}{cc}
\hline \hline$B[\%]$ & $\dot{m}_{f c}[\mathrm{~kg} / \mathrm{s}]$ \\
\hline 20 & 0.003275 \\
15 & 0.002312 \\
10 & 0.001456 \\
5 & 0.00069 \\
\hline \hline
\end{tabular}

Table 6. Simulation matrix for parallel film cooling cases with sonic injection. Checkmarks indicate cases that were run and x-marks indicate cases not run.

\begin{tabular}{|c|c|c|c|c|c|c|c|c|c|c|c|c|c|}
\hline \multicolumn{2}{|c|}{ Species } & \multicolumn{4}{|c|}{$\mathbf{H}_{2}$} & \multicolumn{4}{|c|}{ He } & \multicolumn{4}{|c|}{$\mathbf{N}_{2}$} \\
\hline $\mathbf{T}_{e}[\mathbf{K}]$ & $\mathrm{B}[\%]$ & 20 & 15 & 10 & 5 & 20 & 15 & 10 & 5 & 20 & 15 & 10 & 5 \\
\hline & & $\checkmark$ & $\checkmark$ & $\checkmark$ & $\checkmark$ & $\checkmark$ & $\checkmark$ & $\checkmark$ & $\checkmark$ & $\checkmark$ & $\checkmark$ & $\checkmark$ & $\checkmark$ \\
\hline & & $\checkmark$ & $\checkmark$ & $\sqrt{ }$ & $\sqrt{ }$ & $\checkmark$ & $\checkmark$ & $\sqrt{ }$ & $\checkmark$ & $\sqrt{ }$ & $\checkmark$ & $\checkmark$ & $\sqrt{ }$ \\
\hline
\end{tabular}

\section{Simulation Matrix}

The cooling strategies were parameterized in terms of species, blowing parameter, and nozzle exit temperature for film cooling while species, blowing parameter, and array width and length were varied for transpiration cooling. For a constant fuel mass flow rate of $0.0131 \mathrm{~kg} / \mathrm{s}$, Table 5 shows the required film cooling or transpiration mass flow rate for values of blowing parameter ranging between 5 and $20 \%$.

For evaluating film cooling cases, the systematic methodology for evaluating each concept consisted of first computing a "pathfinding" simulation at a particular combination of species and nozzle exit temperature with $B=20 \%$. This was a test that showed if the particular combination of species and exit temperature were feasible (i.e. substantially reducing autoignition on the forebody). If a particular combination of species and exit temperature reduced autoignition substantially, the blowing parameter was gradually lowered to evaluate the effect of that parameter.

The film cooling cases tested in this study are shown in Tables 6 through 8, which cover the parallel, $10^{\circ}$, and $45^{\circ}$ film cooling strategies. For each case the film cooling channel began at the $\mathrm{x}=200 \mathrm{~mm}$ station. The checkmarks on the tables show both the pathfinding cases (at $B=20 \%$ ) and those additionally run cases to evaluate the effect of decreasing blowing parameter. Cases that are crossed out indicate those not run due to the corresponding pathfinding cases not finding any significant autoignition mitigation.

The transpiration cases tested for this study are shown in Table 9. Widths are percentages of the full width of the flowpath centered on the centerline and lengths are percentages of the length from the beginning of the transpiration patch at $\mathrm{x}=200 \mathrm{~mm}$ to the notional cowl closure location at $\mathrm{x}=713 \mathrm{~mm}$. Similar to the film cooling cases, transpiration cases at high blowing levels were tested first in order to establish the effectiveness of the strategy at those conditions. If negative net oxygen relative to the baseline was consumed at those levels, the blowing parameter was reduced to test the limits of the combination of species and patch size. Negative values of change in oxygen consumed indicate cases where less oxygen was consumed in the

Table 7. Simulation matrix for $10^{\circ}$ film cooling cases with sonic injection. Checkmarks indicate cases that were run and x-marks indicate cases not run.

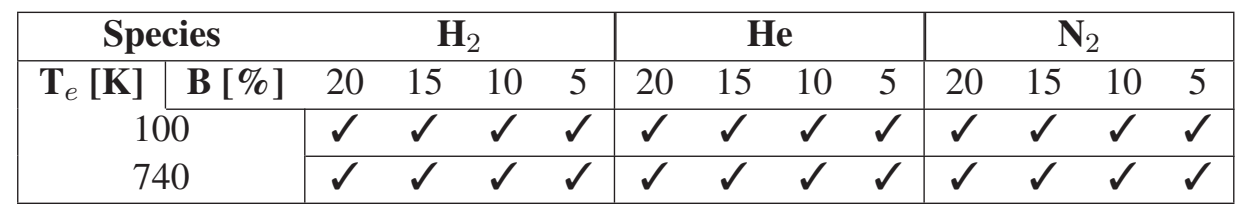


Table 8. Simulation matrix for $45^{\circ}$ film cooling cases with sonic injection. Checkmarks indicate cases that were run and $\mathrm{x}$-marks indicate cases not run.

\begin{tabular}{|c|ccccc|cccc|cccc|}
\hline \multicolumn{10}{|c|}{$\mathbf{H}_{2}$} & \multicolumn{5}{c|}{$\mathbf{H e}$} & \multicolumn{4}{c|}{$\mathbf{N}_{2}$} \\
\hline $\mathbf{T}_{e}[\mathbf{K}]$ & $\mathbf{B}[\%]$ & 20 & 15 & 10 & 5 & 20 & 15 & 10 & 5 & 20 & 15 & 10 & 5 \\
100 & $\checkmark$ & $\boldsymbol{x}$ & $\boldsymbol{x}$ & $\boldsymbol{x}$ & $\checkmark$ & $\checkmark$ & $\checkmark$ & $\checkmark$ & $\checkmark$ & $\boldsymbol{x}$ & $\boldsymbol{x}$ & $\boldsymbol{x}$ \\
740 & $\checkmark$ & $\boldsymbol{x}$ & $\boldsymbol{x}$ & $\boldsymbol{x}$ & $\checkmark$ & $\checkmark$ & $\checkmark$ & $\checkmark$ & $\checkmark$ & $\boldsymbol{x}$ & $\boldsymbol{x}$ & $\boldsymbol{x}$ \\
\hline
\end{tabular}

Table 9. Simulation matrix for transpiration cooling cases with a porosity of $2 \%$. Checkmarks indicate cases that were run and $\mathrm{x}$-marks indicate cases not run.

\begin{tabular}{|c|c|cccc|cccc|cccc|}
\hline \multicolumn{10}{|c|}{$\mathbf{H}_{2}$} & \multicolumn{5}{c|}{ He } & \multicolumn{5}{c|}{$\mathbf{N}_{2}$} \\
\hline W [\%] & $\mathbf{B}[\%]$ & 20 & 15 & 10 & 5 & 20 & 15 & 10 & 5 & 20 & 15 & 10 & 5 \\
100 & $\checkmark$ & $x$ & $x$ & $x$ & $\checkmark$ & $x$ & $x$ & $x$ & $\checkmark$ & $x$ & $x$ & $x$ \\
50 & $\checkmark$ & $x$ & $x$ & $x$ & $\checkmark$ & $x$ & $x$ & $x$ & $\checkmark$ & $x$ & $x$ & $x$ \\
25 & $\checkmark$ & $x$ & $x$ & $x$ & $\checkmark$ & $\checkmark$ & $\checkmark$ & $\checkmark$ & $\checkmark$ & $x$ & $x$ & $x$ \\
\hline L [\%] & B [\%] & 20 & 15 & 10 & 5 & 20 & 15 & 10 & 5 & 20 & 15 & 10 & 5 \\
\hline 50 & $\checkmark$ & $x$ & $x$ & $x$ & $\checkmark$ & $\checkmark$ & $\checkmark$ & $\checkmark$ & $\checkmark$ & $x$ & $x$ & $x$ \\
25 & $\checkmark$ & $x$ & $x$ & $x$ & $\checkmark$ & $x$ & $x$ & $x$ & $\checkmark$ & $x$ & $x$ & $x$ \\
12.5 & $\checkmark$ & $x$ & $x$ & $x$ & $\checkmark$ & $x$ & $x$ & $x$ & $\checkmark$ & $x$ & $x$ & $x$ \\
\hline
\end{tabular}

control volume relative to the baseline case without any cooling.

\section{Results of Film Cooling}

For each strut case run in Tables 6 through 8, the change in consumed oxygen mass flow rate with respect to the baseline case was computed. Figure 13 shows a centerline numerical shadowgraph superimposed with water mass fractions for the baseline case without any film cooling.

The results are shown in Figure 14 for the case of slot injection of hydrogen. It was shown to be possible to inject hydrogen at the wall and have it mitigate autoignition that would otherwise occur without the coolant stream itself autoigniting. This was an important result at the system level because it supports the feasibility of a single fuel storage and cooling system for the purposes of primary and coolant injection. While relatively large values of the blowing parameter were required for elimination of wall ignition, this could be addressed in a flight design by splitting the fueling between the primary injector and the wall slot so that they combine to the desired global equivalence ratio.

Figure 14(a) shows that for tangential hydrogen coolant injection, lower coolant exit temperatures were more advantageous to reducing the amount of oxygen consumed in the sampling region. This is expected

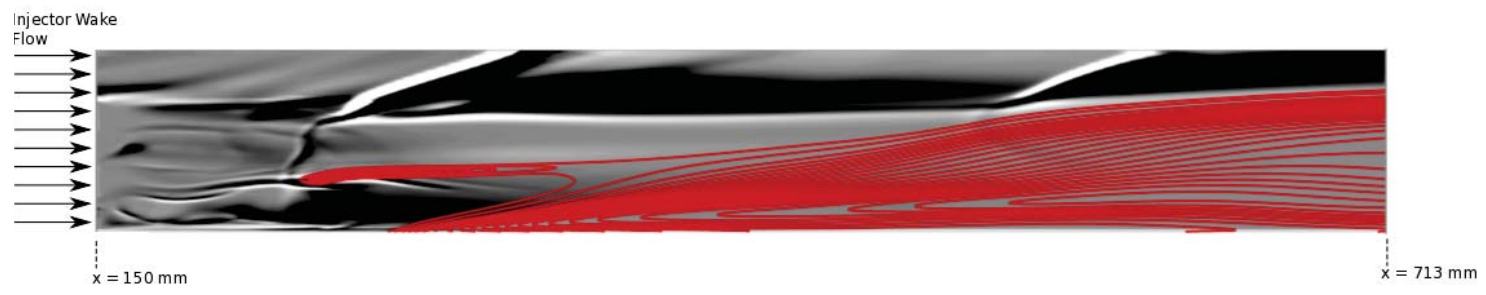

Figure 13. Baseline, reacting flow without autoignition mitigation is shown as numerical shadowgraph overlaid with with water mass fraction contours $Y_{\mathrm{H}_{2} \mathrm{O}}=\mathbf{0 . 0 1}, \mathbf{0 . 0 2}, \ldots, 0.22$. 


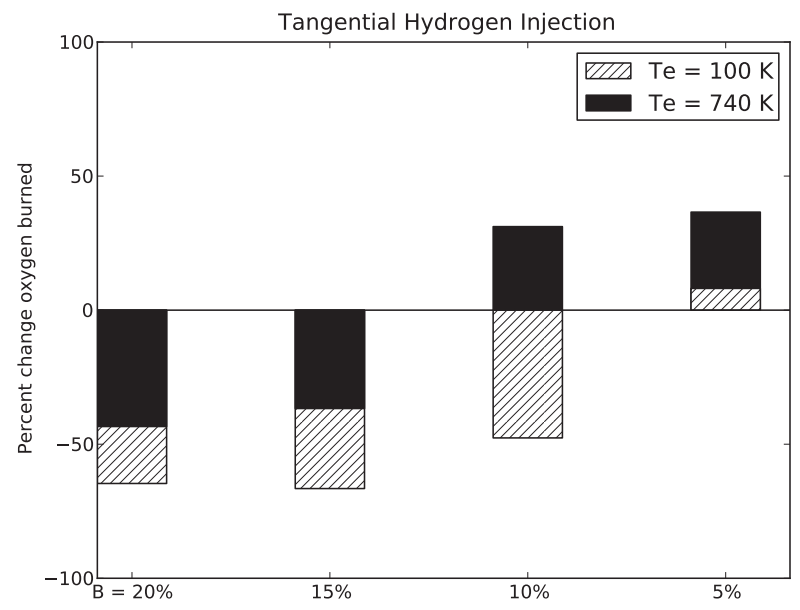

(a)

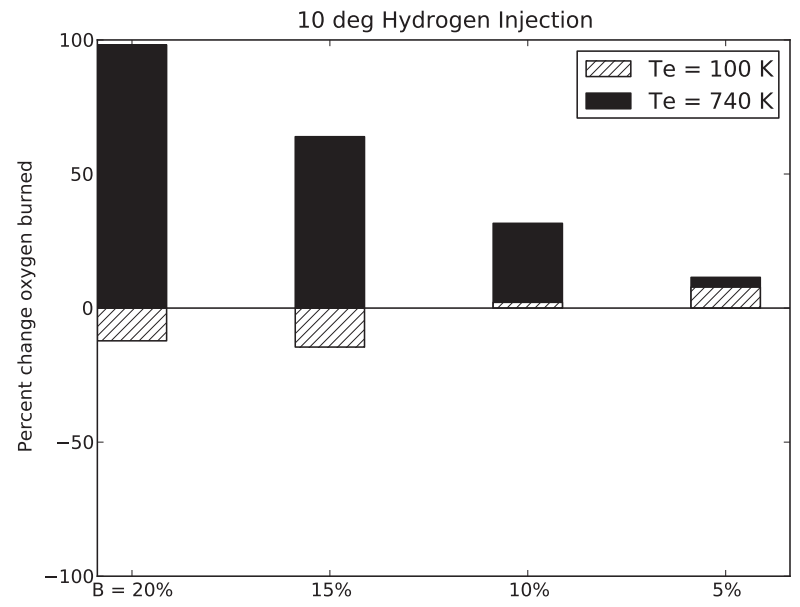

(b)

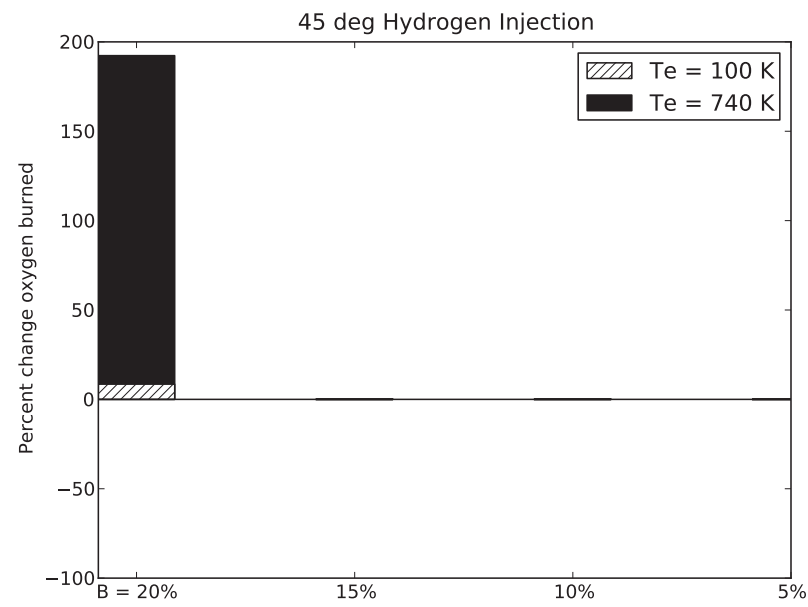

(c)

Figure 14. Changes in mass flow of oxygen consumed for secondary hydrogen injection is shown.

$$
15 \text { of } 24
$$

American Institute of Aeronautics and Astronautics 


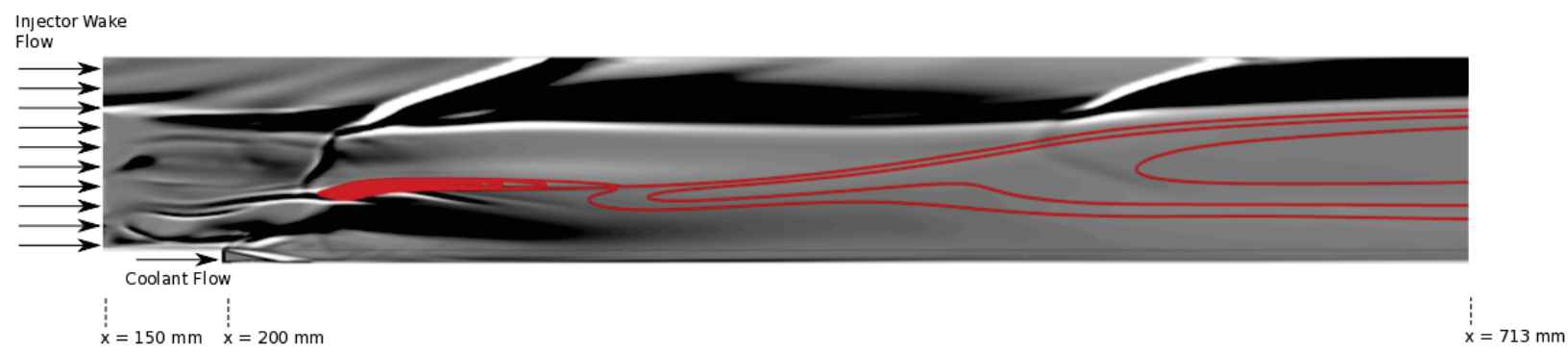

Figure 15. Numerical shadowgraphs overlaid with water contours $Y_{H_{2} O}=\mathbf{0 . 0 1 , 0 . 0 2 , \ldots , 0 . 2 2}$ for tangential film cooling with hydrogen. Coolant temperature of $100 \mathrm{~K}$ and $\mathrm{B}=\mathbf{2 0 \%}$.

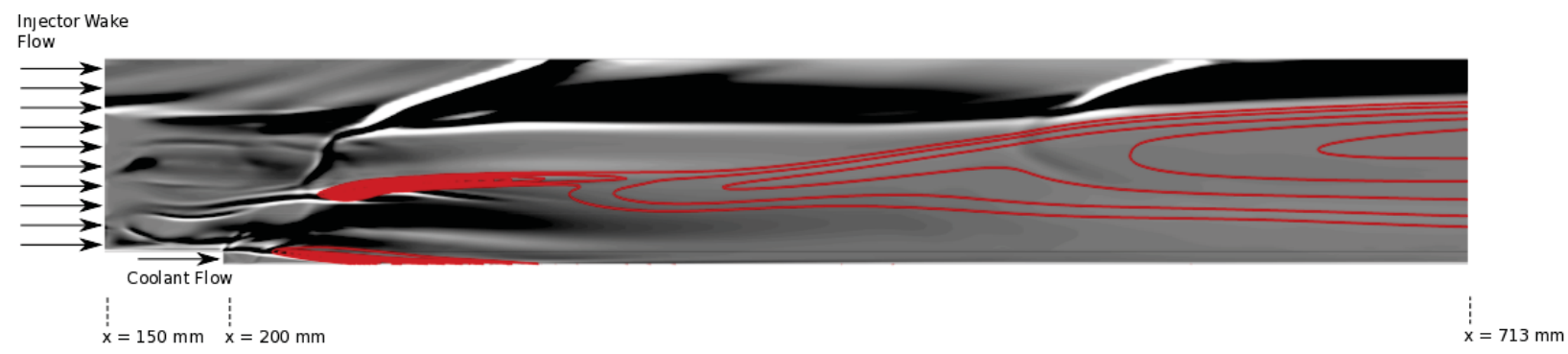

Figure 16. Numerical shadowgraphs overlaid with water contours $Y_{H_{2} O}=\mathbf{0 . 0 1 , 0 . 0 2 , \ldots , 0 . 2 2}$ for tangential film cooling with hydrogen. The coolant temperature is $740 \mathrm{~K}$ and $\mathrm{B}=\mathbf{2 0} \%$.

and related to the increased heat sink capacity of the lower temperature coolant. In addition, the percent reduction in oxygen mass consumed saturates around a $70 \%$ reduction when high coolant flow rates are used. Such cases succeed in eliminating autoignition at the wall but do not greatly affect the mid-stream autoignition zone, as seen in Figure 15. At higher coolant temperatures and blowing rates, the hydrogen coolant in Figure 16 exhibited some initial oxygen consumption while still mitigating a large percentage of the wall burning that would otherwise occur. Below $15 \%$ blowing, the high temperature coolant experienced a rapid drop in performance while the drop in performance for the low temperature coolant occured below $10 \%$ blowing. These drops in performance reflect the presence of hydrogen consumption at the wall moving upstream as the blowing parameter was reduced. At 5\% blowing, slightly more oxygen was consumed relative to the baseline case for the high temperature coolant while for the low temperature coolant the amount of oxygen consumed nearly broke even.

Ten degree slot injection performance for the low temperature hydrogen is shown in Figure 14(b) and indicates significantly reduced effectiveness of hydrogen coolant. For the high temperature coolant at a $20 \%$ blowing rate, a 100\% increase in oxygen consumption was realized as combustion occured almost immediately at the location of injection as shown in Figure 17(b). This was due to the creation of a shock wave at the leading edge of the film cooling slot that caused extensive amounts of coolant consumption. Burning was reduced for the high temperature coolant by reducing the hydrogen mass flow rate to the slot. This may be due to two effects: reduction in strength of the leading-edge shockwave and less combustible fuel having been supplied to the wall region. This combustion zone was delayed relative to the baseline by lowering the coolant temperature as shown in Figure 17(a), although the lowered oxygen consumption rates were marginal. These marginal gains by low temperature ignition were decreased by lowering the blowing parameter, roughly breaking even at $10 \%$ blowing and increasing past $5 \%$ blowing.

Increasing the angle of coolant injection to $45^{\circ}$ caused a $180 \%$ increase in oxygen consumed in the injector wake for a high temperature coolant. This can be observed in the bar chart in Figure 14(c) and the numerical shadowgraph in Figure 18. This was primarily due to the presence of a stronger shock wave 


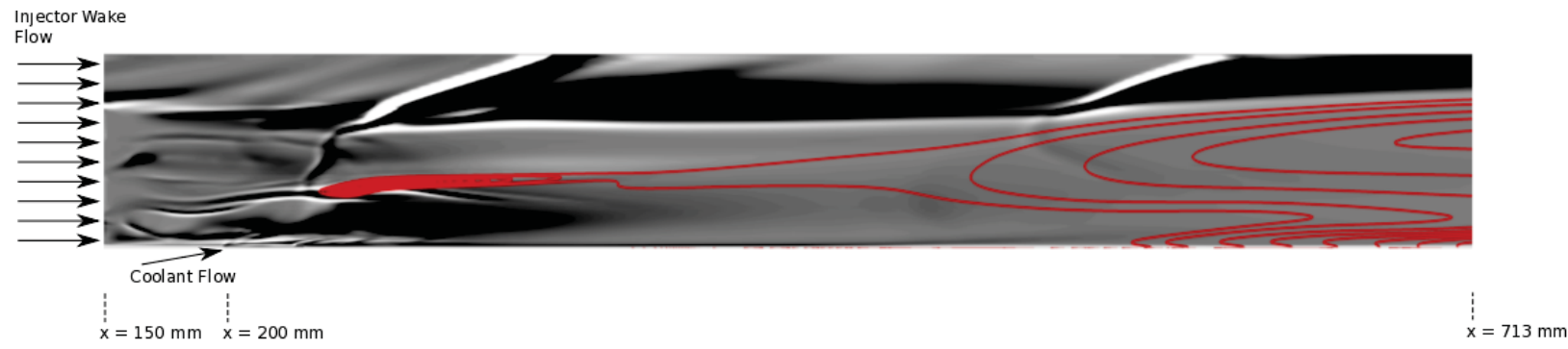

(a)

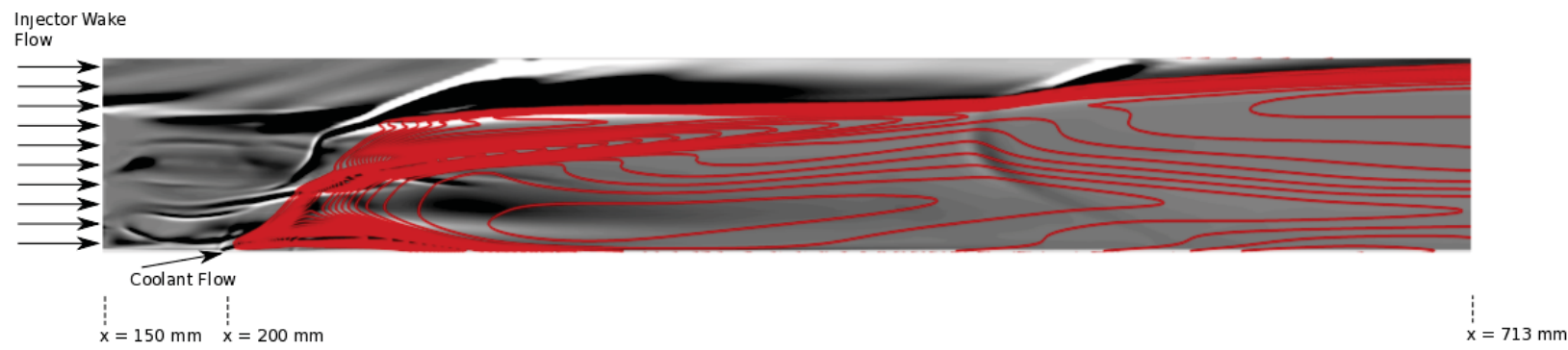

(b)

Figure 17. Numerical shadowgraphs overlaid with water contours $Y_{H_{2} O}=\mathbf{0 . 0 1 , 0 . 0 2 , \ldots , 0 . 2 2}$ for 10 degree film cooling with hydrogen. $B=20 \%$ and ambient temperatures of (a) $100 \mathrm{~K}$ and (b) $740 \mathrm{~K}$ are shown.

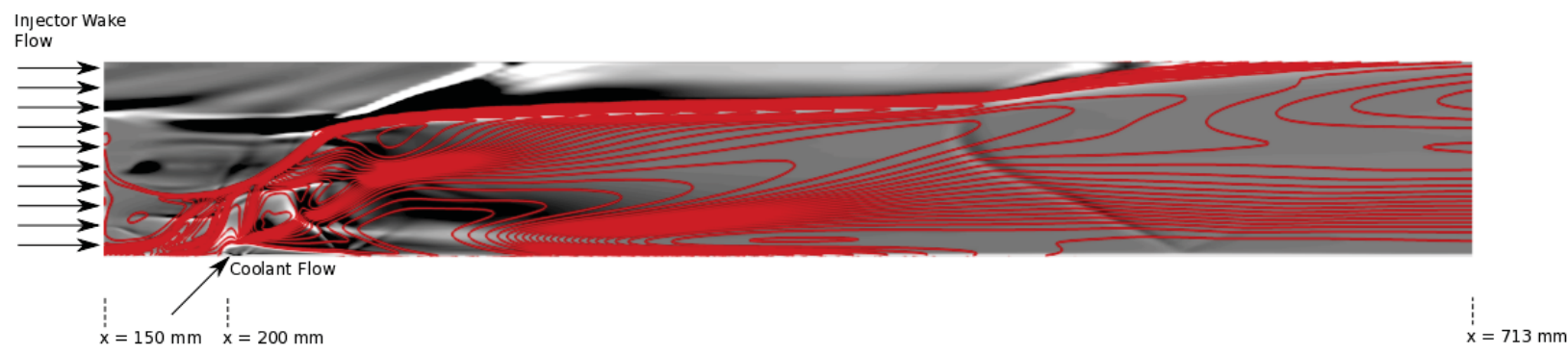

Figure 18. Numerical shadowgraphs overlaid with water contours $Y_{H_{2} O}=\mathbf{0 . 0 1 , 0 . 0 2 , \ldots , 0 . 2 2}$ for 45 degree film cooling with hydrogen. The coolant temperature is $740 \mathrm{~K}$ and $\mathrm{B}=20 \%$.

produced by greater obstruction of the primary flow by the coolant. Lowering the injection temperature nearly broke even the amount of oxygen consumption occurring. Overall, it appears that the slot injection of hydrogen at large angles to the primary flow is inadvisable relative to tangential or even low-angle injection.

The performance of helium slot injection for tangential, $10^{\circ}$, and $45^{\circ}$ injection angles is shown in Figure 19. For the cases tested, the use of helium as a coolant was always able to provide mitigation of ignition relative to the baseline. For both tangential and angled injection, helium was able to meet or outperform hydrogen when compared on the bases of blowing rate and coolant temperature. This can be attributed to helium being an inert species.

At high tangential blowing rates of helium, Figure 19(a) shows that helium was able to achieve similar performance to hydrogen at both coolant temperatures. Unlike hydrogen, helium was not subject to the coolant consumption observed in the hydrogen case. This allowed the helium coolant to experience a more gradual dropoff in performance compared to hydrogen as blowing was decreased. As the blowing parameter was decreased below $15 \%$, low temperature helium experienced degradation in autoignition mitigation capacity compared to high temperature helium. This was because the low temperature helium was traveling 


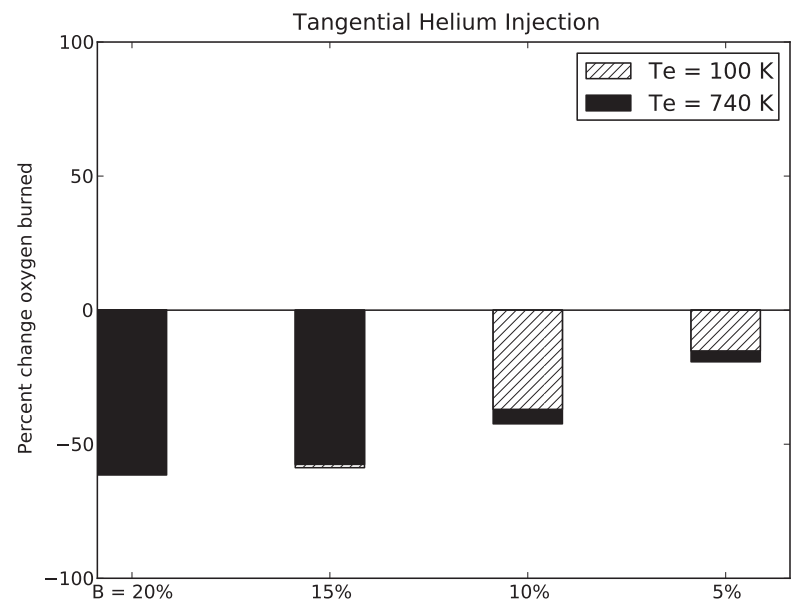

(a)

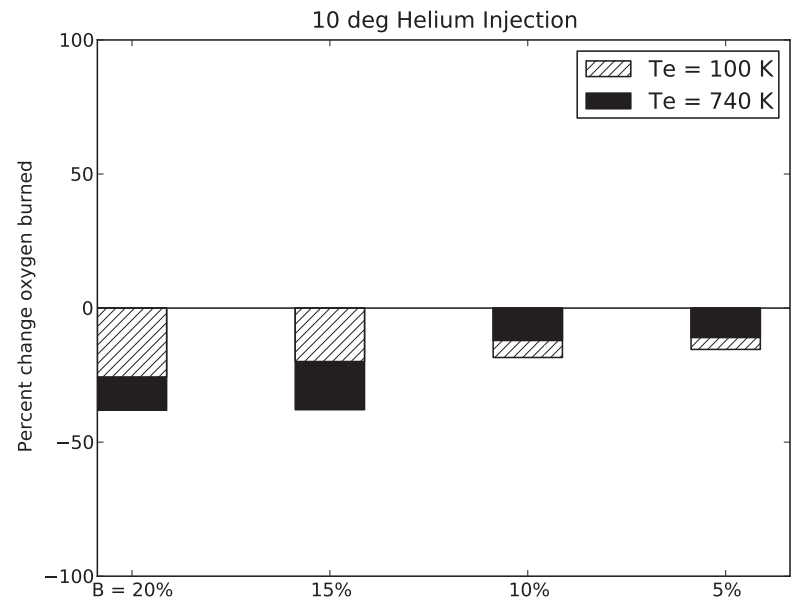

(b)

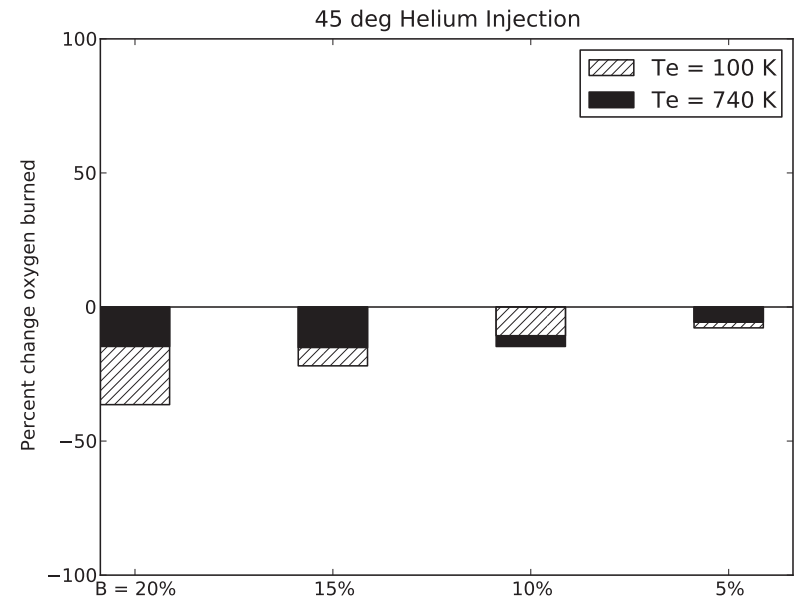

(c)

Figure 19. Changes in mass flow of oxygen consumed for secondary helium injection is shown.

$$
18 \text { of } 24
$$

American Institute of Aeronautics and Astronautics 


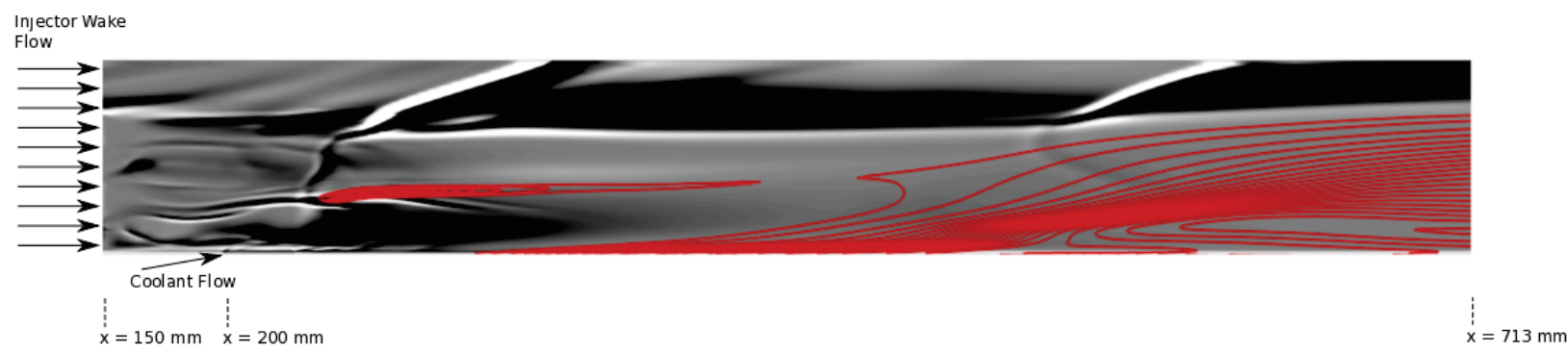

(a)

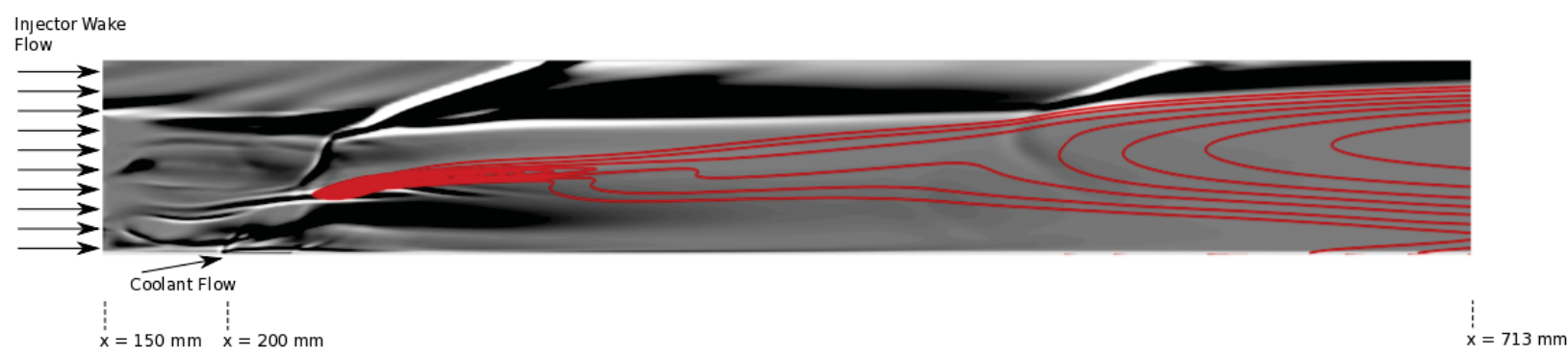

(b)

Figure 20. Numerical shadowgraphs overlaid with water contours $Y_{H_{2} O}=\mathbf{0 . 0 1 , 0 . 0 2 , \ldots , 0 . 2 2}$ for 10 degree film cooling with helium. $B=15 \%$ and ambient coolant temperatures of (a) $100 \mathrm{~K}$ and (b) $740 \mathrm{~K}$ are shown.

at a lower velocity versus the high temperature case. Therefore, more oxygen consumption was occurring in the performance sampling region due to the shortened induction distances. It should also be noted that at low, 5\% blowing levels, helium injection was still able to mitigate a small amount of autoignition, whereas hydrogen had excess burning at the same level of blowing.

Over the range of blowing parameter values tested, $10^{\circ}$ injection of helium shown in Figure 19(b) displayed worse performance relative to tangential helium injection. Compared to hydrogen, however, performance was better overall as there was no excess oxygen consumption relative to the baseline case. Performance degradation as blowing was reduced was more gradual for low temperature helium versus the high temperature cases, which experienced a sharp drop in performance below $B=15 \%$, with the general trend resembling a step function over the blowing parameter range tested. This was because at $B=15 \%$, high temperature helium had a higher pressure of $12,700 \mathrm{~Pa}$ and achieved the "cushioning" effect initially desired for angled film cooling and mitigates ignition at the wall, shown in Figure 20(b). Lowering the blowing parameter below $15 \%$ eliminated this cushioning effect. Low temperature helium at $B=15 \%$, with a lower pressure of $4600 \mathrm{~Pa}$, did not have the same cushioning effect as shown in Figure 20(a).

Injecting helium at a $45^{\circ}$ angle to the main flow produced overall lowered performance relative to the $10^{\circ}$ case, although there are some interesting features that can be observed in Figure 19(c). First, for low temperature helium, the performance at high levels of blowing was similar to the same case for low angle injection. For high temperature helium, a well-defined local maximum in magnitude of oxygen consumption was observed at lower blowing rates. This was due to the tradeoff between high amounts of shock-induced burning at higher blowing levels with lower levels of heat sink capability at low levels of blowing. Therefore, the decrease in oxygen consumed between $20 \%$ and $10 \%$ blowing can be attributed to the decrease in flow obstruction (and subsequent high temperature, shocked regions) and the increase in oxygen consumed between $10 \%$ and $5 \%$ can be attributed to decreased cooling capacity. For the low temperature case, monotonically decreasing cooling capacity was witnessed over the entire range of blowing parameters because the coolant pressure at $B=20 \%$, low temperature blowing ( $6620 \mathrm{~Pa}$ ) was less than that for $B=10 \%$ high temperature blowing ( $8000 \mathrm{~Pa})$. Thus, no local minimum was observed in the low temperature case. 
The performance of nitrogen is shown in Figure 21. Overall it was evident that nitrogen was a relatively poor performer in mitigating autoignition when compared to hydrogen and helium. Two drawbacks nitrogen had over hydrogen and helium at the same temperatures and blowing levels were its relatively low specific heat with respect to mass and the low velocities with which it issued from the sonic slot. The first detriment impacted the ability of the coolant to act as a heat sink to the shear layer near the wall. The second detriment impacted the ability of the coolant to convect the hot flow downstream and delay the occurrence of ignition once the cooling ability of the coolant was saturated.

\section{Results of Wall Transpiration}

For wall transpiration, the cases indicated by checkmarks in Table 9 were simulated to convergence with the amount of oxygen consumed analyzed using the same methodology as for the film cooling case. In addition, it was decided that any cases susceptible to the bleeding of main flow into the simulated plenum, a disastrous condition that would subject the internal transpiration system to hot gases, were failure cases. Finally, the plenum pressure was tracked by the simulation in order to arrive at an idea of the system demands for transpiration cooling.

Based on the above criteria, only a subset of cases in Table 9 were deemed to be feasible. Cases with hydrogen injection had the issue of causing autoignition near the leading edge of the transpiration patch behind the leading edge shock wave, shown in Figure 22. Injection of nitrogen as a coolant was demonstrated to be an ineffective cooling strategy in general for the same reasons as before (e.g. low heat capacity per unit mass), with the additional issue that the low plenum pressures associated with nitrogen tended to allow flow to bleed into the plenum.

Of the helium cases tested, only the $25 \%$ width and $50 \%$ length cases were shown to be able to mitigate the presence of autoignition by any amount. However, only high values of blowing were shown to mitigate the presence of autoignition, and even then the gains were only minimal. Figure 23 shows that the oxygen consumption characteristics of the best performing transpiration cases were similar to the baseline case without any cooling. This is because the transpiration cooling strategy injected fluid in the main stream at much smaller velocities relative to the main flow, severely reducing the cooling capacity of the fluid even for a high specific heat species such as helium. Figure 24 shows the performance of helium injection for these cases. It was observed that a simple trend of increasing autoignition mitigation with increasing blowing parameter was achieved. At the highest blowing values, helium transpiration had performance that only approached that of tangential nitrogen film cooling. Because such poor performance was gained for the same amounts of mass flow as helium film cooling, it was concluded that transpiration cooling is not advantageous for autoignition mitigation for the conditions studied here.

\section{Concluding Remarks}

The current study of the mitigation of autoignition on the forebody of a hypervelocity vehicle focused on the use of active wall cooling. Two methods of wall cooling were considered: slot injection (both parallel and angled) and wall transpiration. Both strategies were applied as boundary conditions, although the transpiration modeling used in the study allowed for physical reproductions of the presence of localized suction. For each method of cooling, three species were tested: hydrogen, helium, and nitrogen. Hydrogen was chosen because of its systems benefits (by using a single fueling system) and excellent heat capacity at the cost of being a combustible coolant. Helium was chosen as an alternative because of its marginally lower heat capacity versus hydrogen with the additional benefit of being an inert species. Nitrogen was chosen as a third alternative because it is also inert and has improved storage density over helium, although its heat capacity is very low compared to the other two alternatives. Both film and transpiration cooling strategies were evaluated at various levels of blowing. 


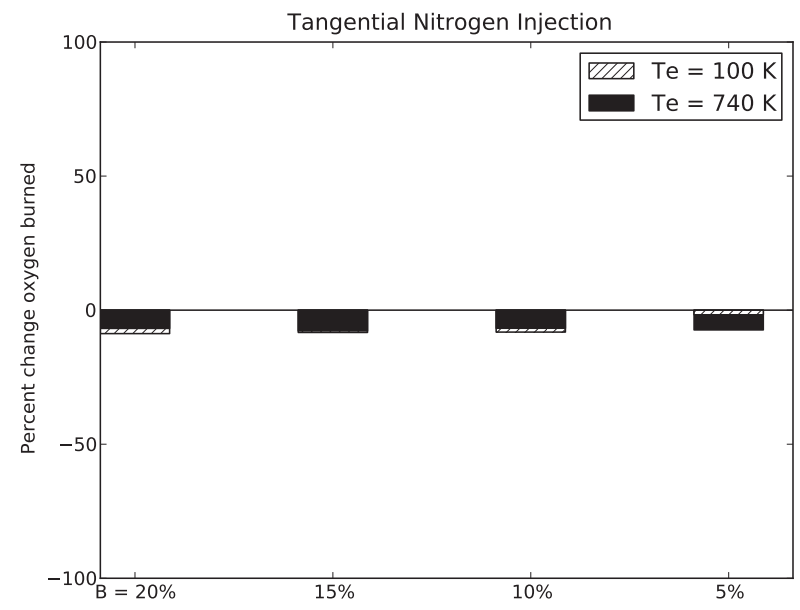

(a)

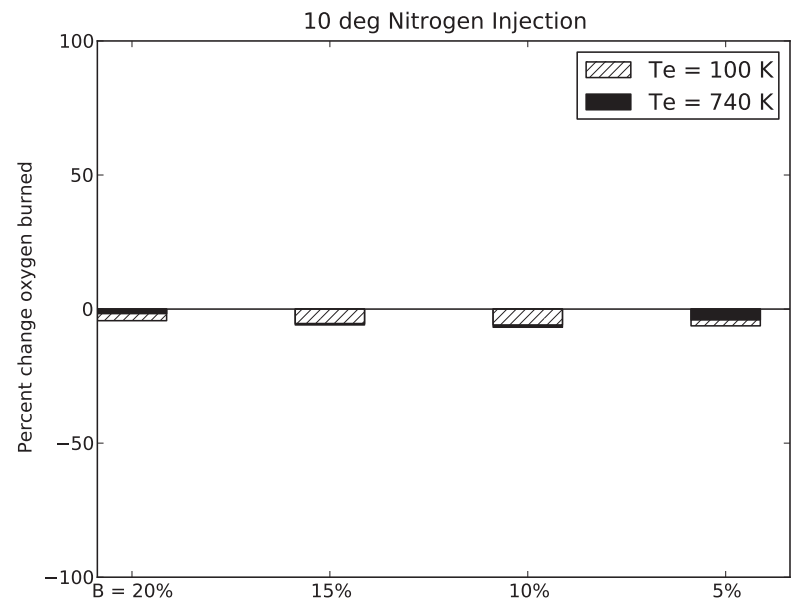

(b)

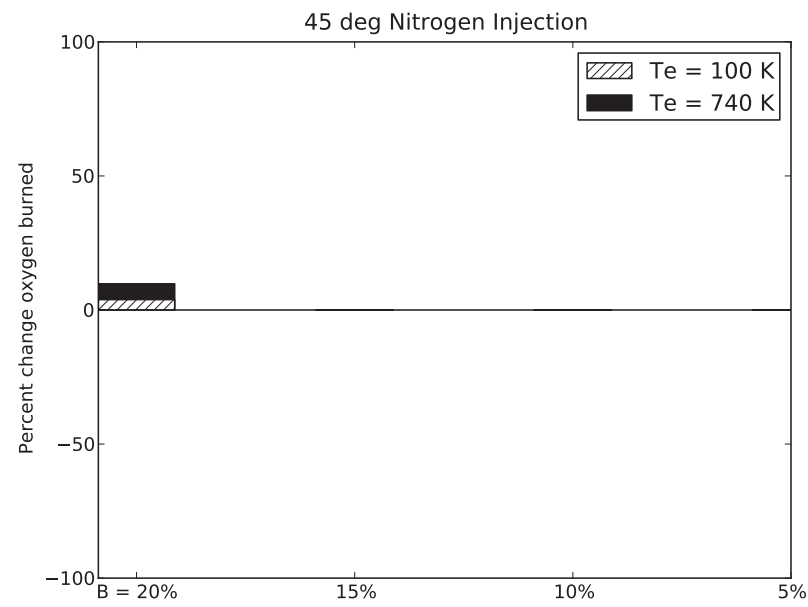

(c)

Figure 21. Changes in mass flow of oxygen consumed for secondary nitrogen injection is shown.

$$
21 \text { of } 24
$$

American Institute of Aeronautics and Astronautics 


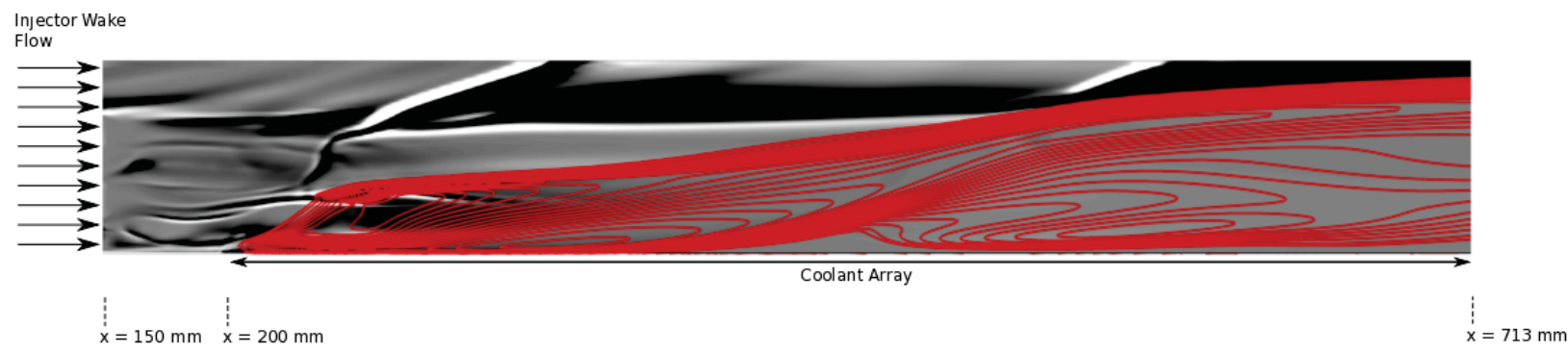

Figure 22. Numerical shadowgraphs overlaid with water contours $Y_{H_{2} O}=\mathbf{0 . 0 1 , 0 . 0 2 , . . . , 0 . 2 2 ~ f o r ~ t r a n s p i r a t i o n ~ c o o l i n g ~ w i t h ~}$ hydrogen. Parameters $B=20 \%$ and $W=25 \%$ are shown.

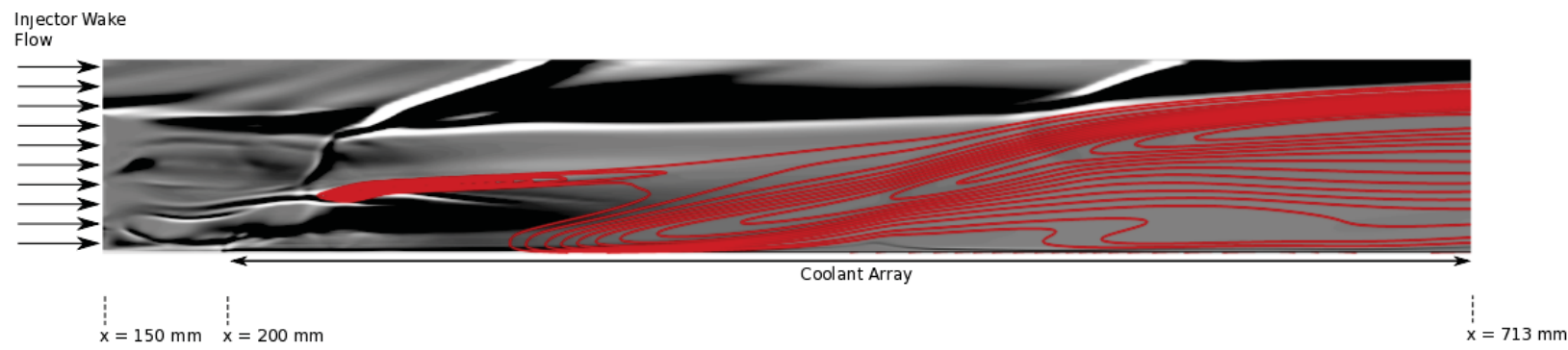

(a)

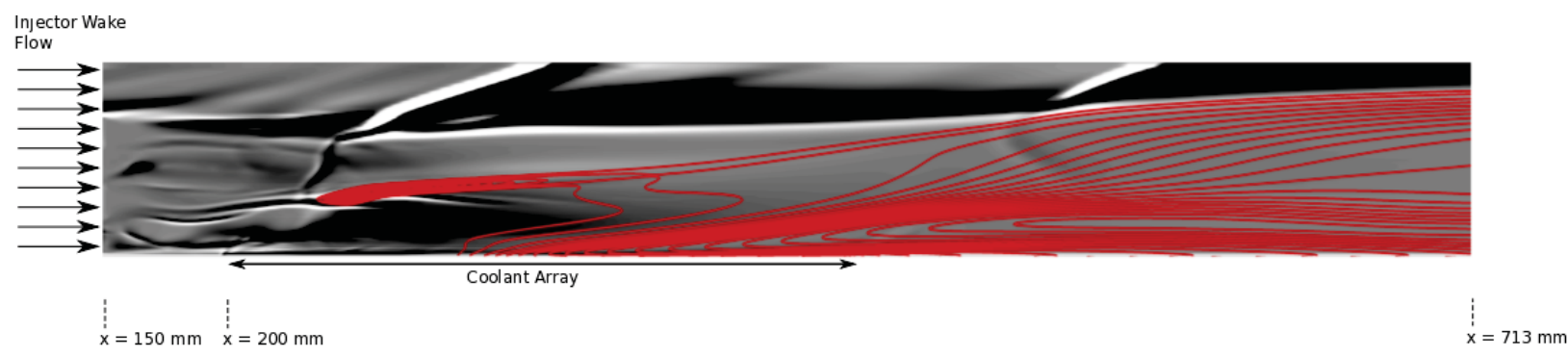

(b)

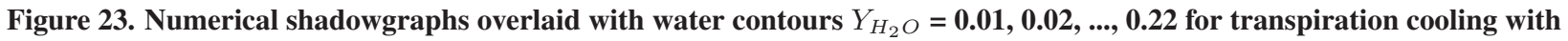
helium. $B=20 \%$ and patch sizings of (a) $\mathrm{W}=\mathbf{2 5 \%}$ and (b) $\mathrm{L}=\mathbf{5 0} \%$ are shown. 


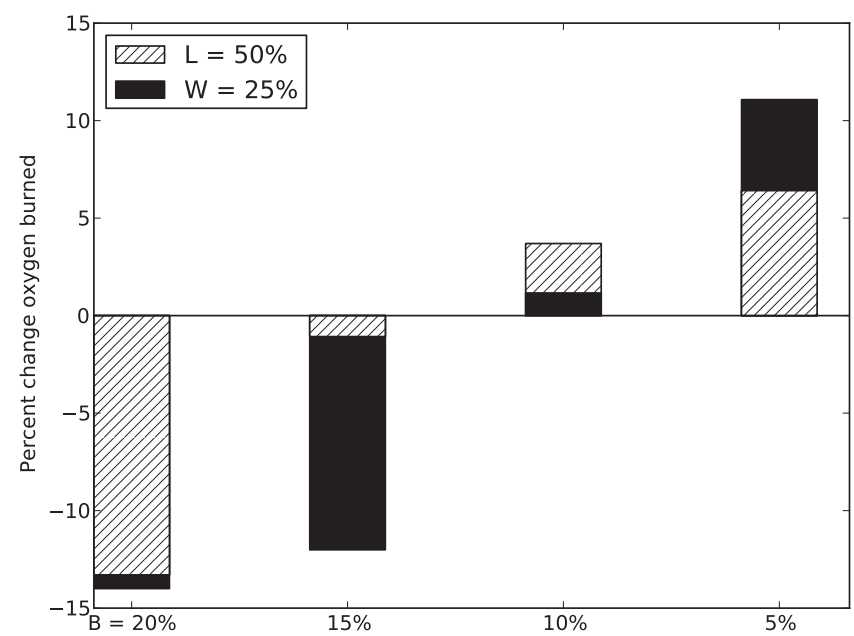

Figure 24. Changes in mass flow of oxygen consumed for secondary helium transpiration are shown.

Baseline reacting cases of the flush-wall, unswept ramp, and strut injectors were simulated without any wall cooling in order to provide a baseline case for comparison. The study of autoignition mitigation focused on the strut injector because transverse injection proved itself to be susceptible to extensive amounts of ignition originating away from the wall. The unswept ramp injector also exhibited redundant ignition characteristics at the wall compared to the strut, just further down stream. Therefore, it was found that the strut provided an excellent geometry for study, with any observations able to potentially be applied to ramp injection.

Film cooling was tested first for hydrogen, helium, and nitrogen over blowing parameters ranging from $5 \%$ to $20 \%$. Two exit temperatures of 100 and $740 \mathrm{~K}$ were tested to determine the effect of fluid total temperature on the cooling characteristics. At high blowing rates and low temperatures, hydrogen was able to eliminate all of the wall autoignition occurring for the strut case. This effect decreased in performance both as coolant temperature increased and/or blowing rate was lowered. Performance also degraded as angled injection was introduced as the coolant itself became susceptible to burning. In general, helium was able to achieve similar levels of performance as hydrogen and sustained better performance at lower levels of blowing due to its inert character. Overall, nitrogen was a poor choice in mitigating autoignition due to its diminished heat capacity with respect to mass. Therefore, it was concluded that tangential hydrogen and helium film cooling are effective methods for autoignition mitigation. If high cooling mass flow rates of hydrogen are required to mitigate autoignition, fueling splits between the primary and film cooling injectors may be considered to target the optimum system global equivalence ratio.

\section{References}

${ }^{1}$ Rubins, P.M. and Bauer, R.C., "Review of Shock-Induced Supersonic Combustion Research and Hypersonic Applications," Journal of Propulsion and Power, Vol. 10, No. 5, 1994, pp. 593-601.

${ }^{2}$ Axdahl, E., Kumar, A., and Wilhite, A., "Study of Forebody Injection and Mixing with Application to Hypervelocity Airbreathing Propulsion," in 48th Joint Propulsion Conference and Exhibit, AIAA-2012-3924, Atlanta, GA, 2012.

${ }^{3}$ Schwartzentruber, T.E., Sislian, J.P., and Parent, B., "Suppression of Premature Ignition in the Pre-Mixed Inlet Flow of a Shcramjet," in 39th Joint Propulsion Conference and Exhibit, AIAA-2003-5187, Huntsville, AL, 2003.

${ }^{4}$ Lehr, H.F., “Experiments on Shock-Induced Combustion,” Astronautica Acta, Vol. 17, 1972, pp. 589-597. 
${ }^{5}$ Ruegg, F.W. and Dorsey, W.W., "A Missile Technique for the Study of Detonation Waves," Journal of research of the National Bureau of Standards, Vol. 66C, No. 1, 1962, pp. 51-58.

${ }^{6}$ Matsuo, A. and Fujiwara, T., "Numerical Simulation of Shock-Induced Combustion Around an Axisymmetric Blunt Body," in 26th Thermophysics Conference, AIAA-1991-1414, Honolulu, HI, 1991.

${ }^{7}$ Axdahl, E., Kumar, A., and Wilhite, A., "Study of Unsteady, Sphere-Driven, Shock-Induced Combustion for Application to Hypervelocity Airbreathing Propulsion," in 47th Joint Propulsion Conference and Exhibit, AIAA-2011-5790, San Diego, CA, 2011.

${ }^{8}$ Terry, J.E. and Caras, G.J., “Transpiration and Film Cooling of Liquid Rocket Nozzles,” Tech. Rep. RSIC-535, U.S. Army Missile Command, Redstone Arsenal, AL, 1966.

${ }^{9}$ Slater, J.W., "Improvements in Modeling 90-Degree Bleed Holes for Supersonic Inlets," Journal of Propulsion and Power, Vol. 28, No. 4, 2012, pp. 773-781.

${ }^{10}$ Andrews, G., Asere, A., Gupta, M., and Mkpadi, M., "Full Coverage Discrete Hole Film Cooling: The Influence of Hole Size,” International Journal of Turbo and Jet Engines, Vol. 2, 1985, pp. 213-225.

${ }^{11}$ Andrews, G., Gupta, M., and Mkpadi, M., "Full Coverage Discrete Hole Film Cooling: Cooling Effectiveness," International Journal of Turbo and Jet Engines, Vol. 2, 1985, pp. 199-212.

${ }^{12}$ Andrews, G., Asere, A., Mkpadi, M., and Tirmahi, A., "Transpiration Cooling: Contribution of Film Cooling to the Overall Cooling Effectiveness," International Journal of Turbo and Jet Engines, Vol. 3, 1986, pp. 245-256.

${ }^{13}$ Brunner, M., "Active Cooling Heat Protection," in Entry Vehicle Systems and Technology Meeting, AIAA-1968-1154, Williamsburg, VA, 1968.

${ }^{14}$ Schuster, J.R. and Lee, T.G., "Application of an Improved Transpiration Cooling Concept to Space Shuttle Type Vehicles," Journal of Spacecraft, Vol. 9, No. 11, 1972, pp. 804-811.

${ }^{15}$ Takita, K. and Masuya, G., "Effects of Combustion and Shock Impingement on Supersonic Film Cooling by Hydrogen," AIAA Journal, Vol. 38, No. 10, 2000, pp. 1899-1906.

${ }^{16}$ White, J. and Morrison, J., "A Pseudo-Temporal Multi-Grid Relaxation Scheme for Solving the Parabolized Navier-Stokes Equations," in 14th Computational Fluid Dynamics Conference, AIAA-1999-3360, Norfolk, VA, 1999.

${ }^{17}$ Edwards, J.R., "A Low-Diffusion Flux-Splitting Scheme for Navier-Stokes Calculations," Computers \& Fluids, Vol. 26, No. 6, 1997, pp. 635-659.

${ }^{18}$ Pulliam, T. and Chaussee, D., “A Diagonal Form of an Implicit Approximate-Factorization Algorithm,” Journal of Computational Physics, Vol. 39, 1981, pp. 347-363.

${ }^{19}$ Menter, F.R., "Zonal Two Equation $k$ - $\omega$ Turbulence Models for Aerodynamic Flows," in 24th Fluid Dynamics Conference, AIAA-1993-2906, Orlando, FL, 1993.

${ }^{20}$ Wilcox, D., "Wall Matching, a Rational Alternative to Wall Functions," in 27th Aerospace Sciences Meeting, AIAA-19890611, Reno, NV, 1989.

${ }^{21}$ Jachimowski, C.J., "An Analytical Study of the Hydrogen-Air Reaction Mechanism With Application to Scramjet Combustion,” Technical Paper 2791, NASA, 1988.

${ }^{22}$ Gardiner, W., ed., Combustion Chemistry, Springer-Verlag, 1984.

${ }^{23}$ Doerffer, P.P. and Bohning, R., "Modelling of Perforated Plate Aerodynamics Performance," Aerospace Science and Technology, Vol. 4, 2000, pp. 525-534.

${ }^{24}$ Baurle, R.A. and Norris, A.T., "A Source-Term Based Boundary Layer Bleed/Effusion Model for Passive Shock Control," in 58th JANNAF Propulsion Meeting, NF1676L-11510, 2011.

${ }^{25}$ Rogers, R.C. and Shexnayder, C.J., "Chemical Kinetic Analysis of Hydrogen-Air Ignition and Reaction Times," Technical Paper 1856, NASA, 1981. 